\title{
Saccharomyces cerevisiae fermentation products (SCFP) stabilize the ruminal microbiota of lactating dairy cows during periods of a depressed rumen $\mathrm{pH}$
}

Hein M. Tun ${ }^{1,2+}$, Shucong Li ${ }^{1+}$, Ilkyu Yoon ${ }^{3}$, Sarah J. Meale ${ }^{4}$, Paula A. Azevedo ${ }^{1}$, Ehsan Khafipour ${ }^{1,5^{*}}$ and Jan C. Plaizier ${ }^{1 *}$ (D)

\begin{abstract}
Background: Effects of Saccharomyces cerevisiae fermentation products (SCFP) on rumen microbiota were determined in vitro and in vivo under a high and a depressed $\mathrm{pH}$. The in vitro trial determined the effects of Original XPC and NutriTek (Diamond V, Cedar Rapids, IA) at doses of 1.67 and $2.33 \mathrm{~g} / \mathrm{L}$, respectively, on the abundances of rumen bacteria under a high $\mathrm{pH}(>6.3)$ and a depressed $\mathrm{pH}$ (5.8-6.0) using quantitative PCR (qPCR). In the in vivo trial eight rumen-cannulated lactating dairy cows were used in a cross-over design. Cows were randomly assigned to SCFP treatments (Original XPC, Diamond V, Cedar Rapids, IA) or control (No SCFP) before two 5-week experimental periods. During the second period, SCFP treatments were reversed. Cows on the SCFP treatment were supplemented with $14 \mathrm{~g} / \mathrm{d}$ of SCFP and $126 \mathrm{~g} / \mathrm{d}$ of ground corn. Other cows received $140 \mathrm{~g} / \mathrm{d}$ ground corn. During the first 4 wk. of each period, cows received a basal diet containing $153 \mathrm{~g} / \mathrm{kg}$ of starch. During week 5 of both periods, the rumen pH was depressed by a SARA challenge. This included replacing $208 \mathrm{~g} / \mathrm{kg}$ of the basal diet with pellets of ground wheat and barley, resulting in a diet that contained $222 \mathrm{~g} / \mathrm{kg}$ DM of starch. Microbial communities in rumen liquid digesta were examined by pyrosequencing, $\mathrm{qPCR}$, and shotgun metagenomics.

Results: During the in vitro experiment, XPC and NutriTek increased the relative abundances of Ruminococcus flavefaciens, and Fibrobacter succinogenes determined at both the high and the depressed pH, with NutriTek having the largest effect. The relative abundances of Prevotella brevis, $R$. flavefaciens, ciliate protozoa, and Bifidobacterium spp. were increased by XPC in vivo. Adverse impacts of the in vivo SARA challenge included reductions of the richness and diversity of the rumen microbial community, the abundances of Bacteroidetes and ciliate protozoa in the rumen as determined by pyrosequencing, and the predicted functionality of rumen microbiota as determined by shotgun metagenomics. These reductions were attenuated by XPC supplementation.
\end{abstract}

Conclusions: The negative effects of grain-based SARA challenges on the composition and predicted functionality of rumen microbiota are attenuated by supplementation with SCFP.

\footnotetext{
*Correspondence: Ehsan_Khafipour@diamondv.com; plaizier@umanitoba.ca

${ }^{+} \mathrm{H}$. M. Tun and S. Li contributed equally to this work.

'Department of Animal Science, University of Manitoba, Winnipeg, MB,

Canada

Full list of author information is available at the end of the article
}

(c) The Author(s). 2020 Open Access This article is licensed under a Creative Commons Attribution 4.0 International License, which permits use, sharing, adaptation, distribution and reproduction in any medium or format, as long as you give appropriate credit to the original author(s) and the source, provide a link to the Creative Commons licence, and indicate if changes were made. The images or other third party material in this article are included in the article's Creative Commons licence, unless indicated otherwise in a credit line to the material. If material is not included in the article's Creative Commons licence and your intended use is not permitted by statutory regulation or exceeds the permitted use, you will need to obtain permission directly from the copyright holder. To view a copy of this licence, visit http://creativecommons.org/licenses/by/4.0/ The Creative Commons Public Domain Dedication waiver (http://creativecommons.org/publicdomain/zero/1.0/) applies to the data made available in this article, unless otherwise stated in a credit line to the data. 


\section{Background}

Healthy and stable rumen microbiota are critical for maintaining efficient nutrient utilization, production and gut health of ruminants $[1,2]$. However, the common practice of feeding diets with high grain and low coarse fiber contents to high-yielding dairy cows in order to meet their energy requirements can reduce gut health by inducing subacute ruminal acidosis (SARA) $[2,3]$. This gut health disorder is defined as a reversible reduction of the rumen $\mathrm{pH}$ below 5.6 and 5.8 for a prolonged period $[1,4,5]$. This disorder can affect the composition and functionality of rumen microbiota by reducing the richness and diversity, reducing the abundances of protozoa and beneficial fibrolytic bacteria and by increasing the abundances of opportunistic pathogenic bacteria [3-5].

A variety of feed supplements are routinely used to enhance production efficiency and rumen function in cattle, including Saccharomyces cerevisiae fermentation products (SCFP). These products are rich in vitamins, minerals, oligosaccharides, organics acids, amino acids, peptides, antioxidants, and $\beta$-glucans that enhance the growth of bacteria [6], protozoa [7], and fungi [3] in the rumen. These bacteria include Fibrobacter succinogenes and Ruminococcus albus that are key digesters of structural carbohydrates in the rumen $[2,6]$.

Recent studies have demonstrated that supplementation with SCFP increases the efficiency of milk production and reduces adverse effects of SARA, such as the depression in rumen $\mathrm{pH}$ and milk fat $[8,9]$. These effects of SCFP may be mediated through their effects on the composition and functionality of rumen microbiota. However, the underlying mechanisms have not yet been sufficiently explored. We, therefore, hypothesized that supplementing with SCFP reduces the adverse impacts of SARA on the composition and functionality of rumen microbiota. This hypothesis was tested in an in vitro and an in vivo trial by determining the effects of SCFP supplementation on microbiome composition and functionality during periods of high and depressed rumen $\mathrm{pH}$.

\section{Results}

\section{In vitro trial}

At the high $\mathrm{pH}$, both XPC and NutriTek increased $(P<0.05)$ the relative abundances of $R$. albus, $R$. flavefaciens, $F$. succinogenes, and $S$. ruminantium compared to the control treatment as determined by qPCR, with NutriTek having the larger increase on $R$. flavefaciens (2.23 vs. 1.71 times, $P<0.05)$ and $S$. ruminantium than XPC (1.84 vs. 1.44 times, $P<0.05)$ (Fig. 1a). At the high $\mathrm{pH}, \mathrm{M}$. elsdenii was not detected. At the depressed $\mathrm{pH}$ (5.8-6.0), both XPC and NutriTek increased $(P<0.05)$ the relative abundances of $R$. flavefaciens, $F$. succinogenes, and $M$. elsdenii as determined by qPCR compared to the control treatment (Fig. 1b). These increases were larger for NutriTek than for XPC for F. succinogenes (3.15 vs. 2.23 times, $P<0.05)$, $M$. elsdenii $(2.11$ vs. 1.57 times, $P<0.05), S$. bovis (1.38 vs. $1.25, P<0.05$ ), and $R$. flavefaciens (4.21 vs. 2.75 times, $P<0.01$ ). However, at the depressed $\mathrm{pH}$, the relative abundances of $R$. albus, $S$. ruminantium and $S$. bovis were not affected by supplementation with SCFP.

\section{In vivo trial \\ Richness, diversity and composition of rumen microbiota based on 16S rRNA gene sequencing}

The SARA challenge reduced all of the richness and diversity measures that were determined, with the exception of the number of reads (Table 1). The SCFP supplementation attenuated $(P<0.05)$ this reduction for the Chao1 (22 vs. $69, P<0.001)$, ACE (167 vs. $480, P<$ $0.001)$, and Shannon indices $(0.35$ vs. $0.97, P<0.001)$ and tended to limit $(0.01$ vs. $0.04, P<0.10)$ this reduction for the Simpson index. The principal coordinate analysis plot based on weighted UniFrac distances showed that the SARA challenge affected the betadiversity of the rumen microbial community, but that this effect was reduced by the supplementation with SCFP (Fig. 2). The effects of the SARA challenge on the relative abundances of phyla determined by $16 \mathrm{~S}$ rRNA gene sequencing also depended on the SCFP treatment (Table 2). The SARA challenge only reduced the relative abundance of Bacteroidetes in the absence of SCFP ( 20.78 vs. $46.84 \%, P<0.05$ ), and only reduced the abundance of Chloroflexi $(0.009$ vs. $0.049 \%, P<0.05)$ when SCFP was supplemented. Across SCFP treatments, the SARA challenge increased $(P<0.05)$ the relative abundances of Firmicutes $(52.1$ vs. $39.3 \%, P<0.05)$ and Proteobacteria (9.7 vs. $1.0 \%, P<0.05)$, reduced those of Spirochaetes (0.4 vs.1.6\%, $P<0.01)$, Tenericutes $(0.8$ vs. $1.8 \%, P<0.01)$, and Cyanobacteria $(0.4$ vs. $0.8 \%, P<$ $0.05)$. SCFP supplementation tended to reduce the relative abundance of Spirochaetes (0.8 vs. $1.2 \%, P=0.06)$ across normal feeding and SARA challenge.

The relative abundances of Succinivibrio and SHD-231 were reduced by the SARA challenge, but these reductions were attenuated by supplementation with SCFP (Table S3). This challenge also affected the abundances of 10 out of the 16 genera with abundances above $1 \%$ of the community, and 19 of the 33 genera with abundances between 0.1 and $1 \%$ of the community. In particular, this challenge decreased the relative abundances of the Paludibacter (1.39 vs. $6.48 \%, P<0.01$ ), Prevotella (10.78 vs. $14.89 \%, P<0.05), \mathrm{BF} 311$ (0.21 vs. $0.89 \%, P<$ $0.01)$, CF231 (0.15 vs. $0.62 \%, P<0.01)$ and YRC22 (0.23 vs. $0.66 \%, P<0.01)$ within Bacteroidetes. Within the phylum Firmicutes, the SARA challenge increased the relative abundances of Butyrivibrio ( 9.40 vs. $5.77 \%, P<$ 

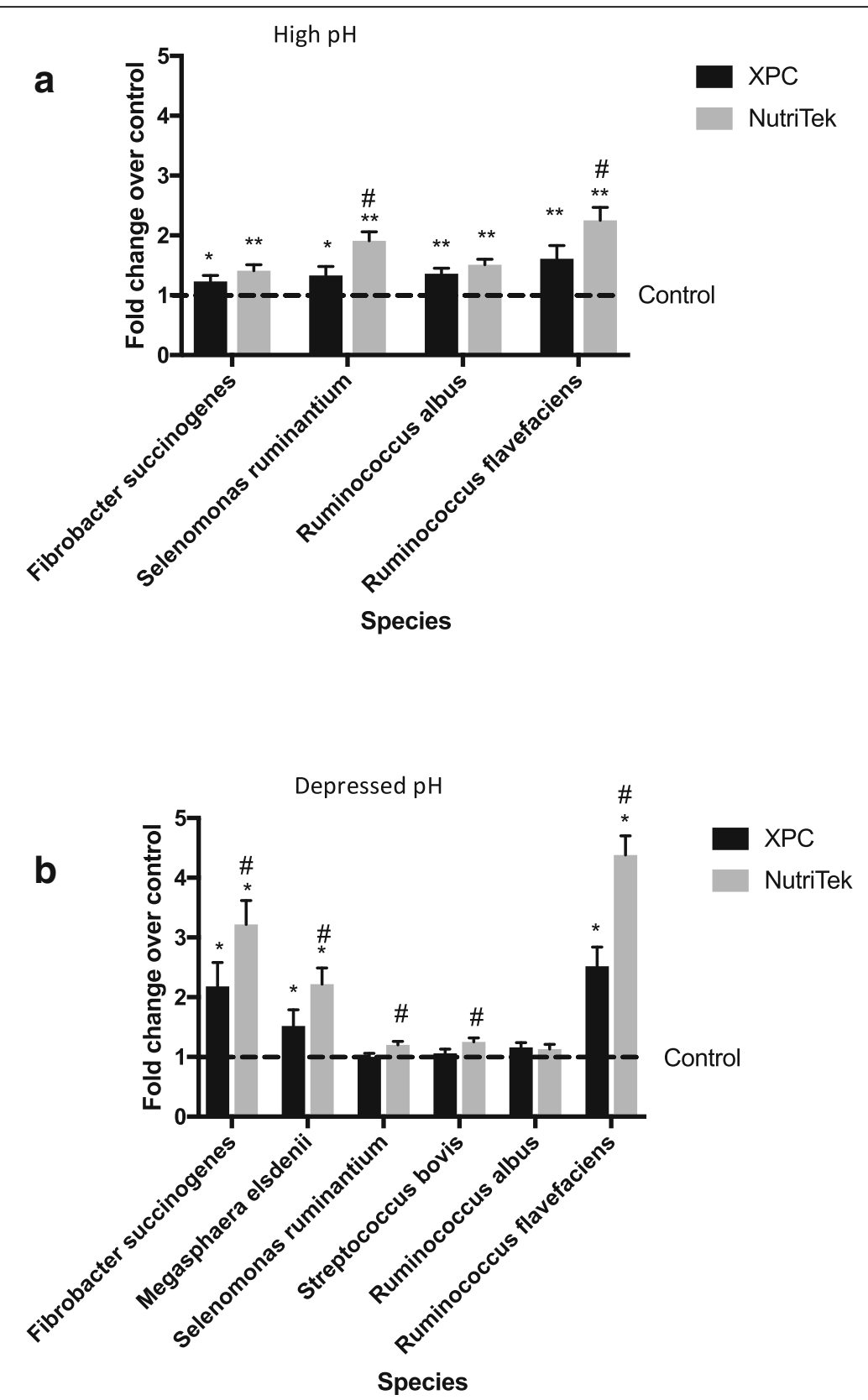

Fig. 1 Fold change compared to the control treatment in populations of selected bacteria due to XPC or NutriTek supplementation determined by $\mathrm{qPCR}$ in vitro under a $(\mathbf{a})$ high $\mathrm{pH}(>6.3)$ or $(\mathbf{b})$ depressed $\mathrm{pH}(5.8-6.0)$ by $\mathrm{qPCR} .{ }^{*}=\mathrm{XPC}$ or NutriTek differ from control $(P<0.05)$. \# $=\mathrm{XPC}$ and NutriTek differ $(P<0.05)$

0.05), Shuttleworthia (0.71 vs. $0.05 \%, P<0.01)$, Staphylococcus $(0.14$ vs. $0.03 \%, P<0.01)$, Lactobacillus $(0.04$ vs. $0.01 \%, P<0.05)$ and Acidaminococcus $(0.11$ vs. $0.00 \%$, $P<0.01)$, whereas it decreased these abundances on of L7A_E1 $(0.00$ vs. $0.04 \%, P<0.01)$ and Succiniclasticum (0.66 vs. $1.59 \%, P<0.01)$. The SARA challenge also reduced $(P \leq 0.04)$ the relative abundances of Treponema $(0.40$ vs. $1.58 \%, \quad P<0.01), \quad$ Pyramidobacter $(0.02$ vs. $0.04 \%, P<0.05)$ and Sutterella $(0.01$ vs. $0.20 \%, P<$ $0.01)$. Of the genera with relative abundances above
$0.1 \%$ of the community, supplementation with SCFP only tended $(P \leq 0.07)$ to increase the abundance of Treponema (0.75 vs. $1.22 \%, P=0.06)$ and of an unidentified genus within Firmicutes (2.18 vs. 4.77\%, $P=0.07)$.

Rumen microbiota abundance based on qPCR analysis The effects of the SARA challenge and SCFP supplementation on the relative abundances of several ruminal bacterial species were determined using qPCR (Fig. 3). The challenge reduced the populations of $F$. succinogenes 
Table 1 Effects of a Saccharomyces cerevisiae fermentation product (SCFP) and a subacute ruminal acidosis (SARA) challenge on richness and diversity indices of rumen bacterial communities calculated from 165 rRNA gene sequencing

\begin{tabular}{|c|c|c|c|c|c|c|c|c|}
\hline \multirow[t]{2}{*}{ Item } & \multicolumn{2}{|l|}{ No SCFP } & \multicolumn{2}{|l|}{ SCFP } & \multirow[t]{2}{*}{ SEM $^{1}$} & \multirow[b]{2}{*}{ SARA } & \multicolumn{2}{|c|}{$\boldsymbol{P}$-value } \\
\hline & Control & SARA & Control & SARA & & & SCFP & SARA *SCFP \\
\hline Number of Reads & 2557 & 3927 & 3126 & 4697 & 833 & 0.1 & 0.44 & 0.91 \\
\hline Observed Species & $197 a$ & $128 b$ & $196 a$ & $174 b$ & 15 & 0.01 & 0.14 & 0.12 \\
\hline Chaol & $741^{a}$ & $337^{b}$ & 643 & 548 & 59 & $<0.001$ & 0.45 & 0.01 \\
\hline ACE & $839^{a}$ & $359^{b}$ & 779 & 612 & 75 & $<0.001$ & 0.3 & 0.02 \\
\hline Shannon & $5.88^{\mathrm{a}}$ & $4.91^{\mathrm{b}}$ & 5.88 & 5.53 & 0.19 & $<0.001$ & 0.17 & 0.05 \\
\hline Simpson & $1.97^{x}$ & $1.93^{y}$ & 1.98 & 1.97 & 0.02 & 0.01 & 0.2 & 0.08 \\
\hline InvSimpson & $63^{\mathrm{a}}$ & $22^{\mathrm{b}}$ & $65^{\mathrm{a}}$ & $50^{b}$ & 5 & 0.01 & 0.22 & 0.19 \\
\hline
\end{tabular}

${ }^{1}$ SEM standard error of mean

a, b LSmeans with different letters within SCFP treatment (No SCFP or SCFP) differ $(P<0.05)$

$x, y$ LSmeans with different letters within SCFP treatment (No SCFP or SCFP) tend to differ $(P<0.10)$

$2 \log _{2}$ fold $(P<0.05)$, Treponema bryantii $2.3 \log _{2}$ fold $(P<0.05)$, Prevotella brevis $\left(1 \log _{2}\right.$ fold, $(P<0.05)$, and ciliate protozoa $2 \log _{2}$ fold $(P<0.05)$, and tended to reduce $(P<0.10)$ that of Clostridium perfringens $0.66 \log _{2}$ fold $(P<0.01)$. In contrast, the SARA challenge increased $(P<0.05)$ the populations of $R$. albus $1.6 \log _{2}$ fold $(P<0.05)$, Prevotella albensis $2.3 \log _{2}$ fold $(P<0.05)$, M. elsdenii $6 \log _{2}$ fold $(P<0.05)$, and Lactobacillus spp. $1 \log _{2}$ fold $(P<0.05)$. Supplementation of SCFP increased $(P<0.05)$ the abundances of Bifidobacterium spp. $1.2 \log _{2}$ fold $(P<0.5), R$. flavefaciens $1.4 \log _{2}$ fold $(P<0.05), P$. brevis $1.2 \log _{2}$ fold, and ciliate protozoa 3.2

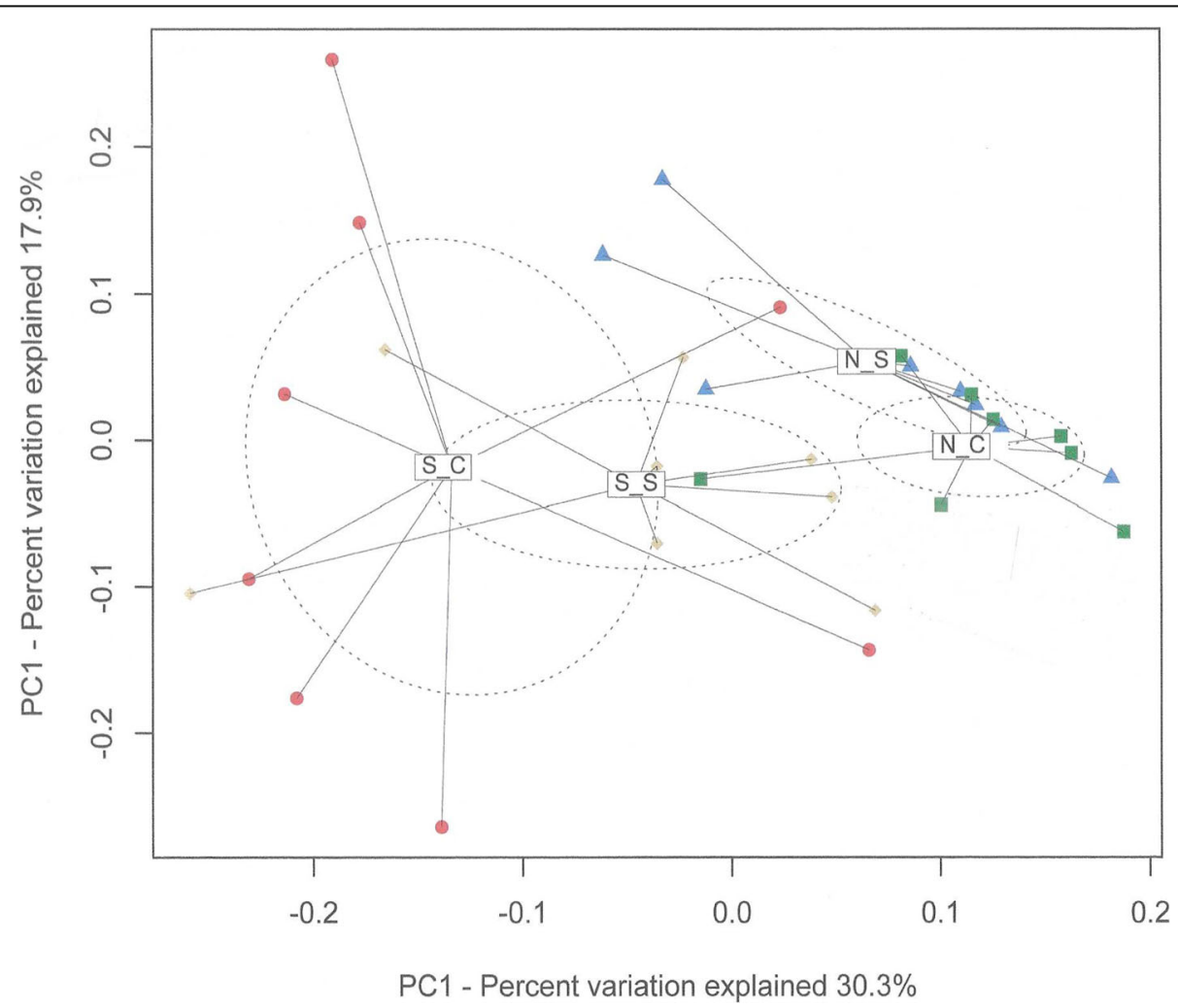

Fig. 2 Two-dimensional PCoA plot based on weighted UniFrac distance matrix illustrates variation in rumen bacterial communities affected by subacute ruminal acidosis (SARA) challenge and supplementation of Saccharomyces cerevisiae fermentation products (SCFP). The significance of the effects of SARA challenge, SCFP supplementation and their interaction were $P=0.001, P=0.64$, and $P=0.05$, respectively. Abbreviations in figure: N_C, normal diet without SCFP supplementation; N_S, normal diet with SCFP supplementation; S_C, SARA challenge without SCFP supplementation; S_S, SARA challenge with SCFP supplementation 
Table 2 Relative abundances of ruminal bacterial phyla affected by Saccharomyces cerevisiae fermentation products (SCFP) and a subacute ruminal acidosis (SARA) challenge as determined by 165 rRNA gene sequencing

\begin{tabular}{|c|c|c|c|c|c|c|c|c|}
\hline \multirow[t]{2}{*}{ Phylum } & \multicolumn{2}{|c|}{ No SCFP } & \multicolumn{2}{|l|}{ SCFP } & \multirow[t]{2}{*}{$\mathrm{SEM}^{1}$} & \multicolumn{3}{|c|}{ P-value } \\
\hline & Control & SARA & Control & SARA & & SARA & SCFP & SARA* SCFP \\
\hline \multicolumn{9}{|c|}{ Above $0.1 \%$ community } \\
\hline Bacteroidetes & $46.84^{\mathrm{a}}$ & $20.78^{b}$ & 40.57 & 32.49 & 4.72 & $<0.01$ & 0.44 & 0.02 \\
\hline Firmicutes & 35.08 & 53.86 & 43.44 & 50.25 & 5.06 & 0.04 & 0.69 & 0.3 \\
\hline Proteobacteria & 1.12 & 13.88 & 0.78 & 5.5 & 2.74 & 0.02 & 0.39 & 0.46 \\
\hline Spirochaetes & $1.41^{x}$ & $0.11^{y}$ & $1.79^{x}$ & $0.69^{y}$ & 0.22 & $<0.01$ & 0.06 & 0.68 \\
\hline Tenericutes & $1.85^{x}$ & $0.45^{y}$ & $1.84^{x}$ & $1.06^{y}$ & 0.24 & $<0.01$ & 0.24 & 0.22 \\
\hline Cyanobacteria & $1.05^{\mathrm{a}}$ & $0.41^{\mathrm{b}}$ & $0.60^{a}$ & $0.44^{\mathrm{b}}$ & 0.15 & 0.02 & 0.23 & 0.22 \\
\hline SR1 & 0.75 & 0.43 & 0.53 & 0.22 & 0.2 & 0.14 & 0.32 & 0.18 \\
\hline TM7 & 0.41 & 0.28 & 0.31 & 0.23 & 0.08 & 0.22 & 0.36 & 0.99 \\
\hline \multicolumn{9}{|c|}{ Between 0.01 and $0.1 \%$ of community } \\
\hline Verrucomicrobia & $0.23 a$ & $0.02 b$ & $0.36 a$ & $0.04 b$ & 0.05 & $<0.01$ & 0.17 & 0.74 \\
\hline Actinobacteria & 0.052 & 0.072 & 0.047 & 0.032 & 0.029 & 0.94 & 0.51 & 0.6 \\
\hline Chloroflexi & 0.005 & 0.016 & $0.049^{\mathrm{a}}$ & $0.009^{b}$ & 0.01 & 0.25 & 0.13 & 0.05 \\
\hline Elusimicrobia & $0.033^{\mathrm{a}}$ & $0.002^{b}$ & $0.042^{\mathrm{a}}$ & $0.005^{b}$ & 0.013 & 0.02 & 0.8 & 0.87 \\
\hline Fibrobacteres & 0.115 & 0.047 & 0.088 & 0.082 & 0.028 & 0.16 & 0.89 & 0.24 \\
\hline Lentisphaerae & 0.095 & 0 & 0.042 & 0.011 & 0.021 & 0.16 & 0.89 & 0.24 \\
\hline Planctomycetes & 0.021 & 0.016 & 0.046 & 0.008 & 0.013 & 0.13 & 0.54 & 0.26 \\
\hline Synergistetes & 0.016 & 0 & 0.025 & 0.009 & 0.009 & 0.16 & 0.39 & 0.93 \\
\hline
\end{tabular}

'SEM standard error of mean

a, b LSmeans with different letters within SCFP treatment (No SCFP or SCFP) differ $(P<0.05)$

$x, y$ LSmeans with different letters within SCFP treatment (No SCFP or SCFP) tend to differ $(P<0.10)$

$\log _{2}$ fold $(P<0.05)$, and tended to increase that of $R$. albus $1 \log _{2}$ fold $(P<0.10)$, T. bryantii $0.7 \log _{2}$ fold $(P<$ $0.10)$ and Anaerovibrio lipolytica $1.1 \log _{2}$ fold $(P<0.10)$.

\section{Shotgun metagenomic analyses}

Shotgun metagenomic sequencing showed that, across SCFP treatments, the SARA challenge tended to increase the relative abundance of Firmicutes $(44.3$ vs. $37.6 \%, P=$ 0.09), whereas it decreased those of Fibrobacteres $(0.27$ vs. $0.64 \%, P<0.01)$, Spirochaetes $(1.69$ vs. $4.10 \%, P<$ $0.01)$, Tenericutes (2.95 vs. $4.73 \%, P<0.01)$ and Verrucomicrobia ( 0.01 vs. $0.16 \%, P<0.01)$ (Table 3$)$. None of the abundances of the identified bacterial or eukaryote phyla were affected by SCFP, nor by the interaction between the SARA challenge and the SCFP treatments. In contrast, the relative abundance of archaea increased due to the SARA challenge in the absence of SCFP ( 1.15 vs. $0.71 \%, P<0.05)$. However, the challenge reduced this abundance when SCFP was supplemented $(0.70$ vs. $1.80 \%, P<0.05)$.

\section{Microbiome functions annotated by shotgun metagenomic sequencing}

A total of 103.4 gigabytes (GB) of sequences were obtained from shotgun metagenomic sequencing, with an average of $10 \mathrm{M}$ sequences per sample. The betadiversity of the ruminal microbial community's composition was affected by SCFP treatment and by the SARA challenge (Fig. 4). The ruminal microbial community's functionality-based beta-diversity was also affected by SCFP $(P<0.05)$, but the impact of SCFP was greater during the SARA challenge than during normal feeding (Fig. 5). Functional annotations of the shotgun metagenomic sequences revealed that across SCFP treatments, the SARA challenge increased $(P<0.05)$ the "metabolism of aromatic compounds", and tended $(P<0.10)$ to increase "protein metabolism" (Table 4). The SARA challenge only increased "sulfur metabolism" and increased "cell wall and capsule" in the absence of SCFP supplementation. The challenge only tended to reduce "nucleotides and nucleosides" when SCFP was supplemented. Supplementation with SCFP only increased "secondary metabolism" and "phosphorus metabolism" in the absence of SARA induction.

Using single class LEfSe analysis, two bacterial species belonging to unclassified Panibacillaceae (Fig. 6a) and Spriochaetaceae (Fig. 6a), and two archaeal taxa, Methanobacteria (Fig. 6b) and unclassified Euryarchaeota (Fig. 6b) were identified as microbial biomarkers that were affected by SCFP. The abundance of species belonging to 


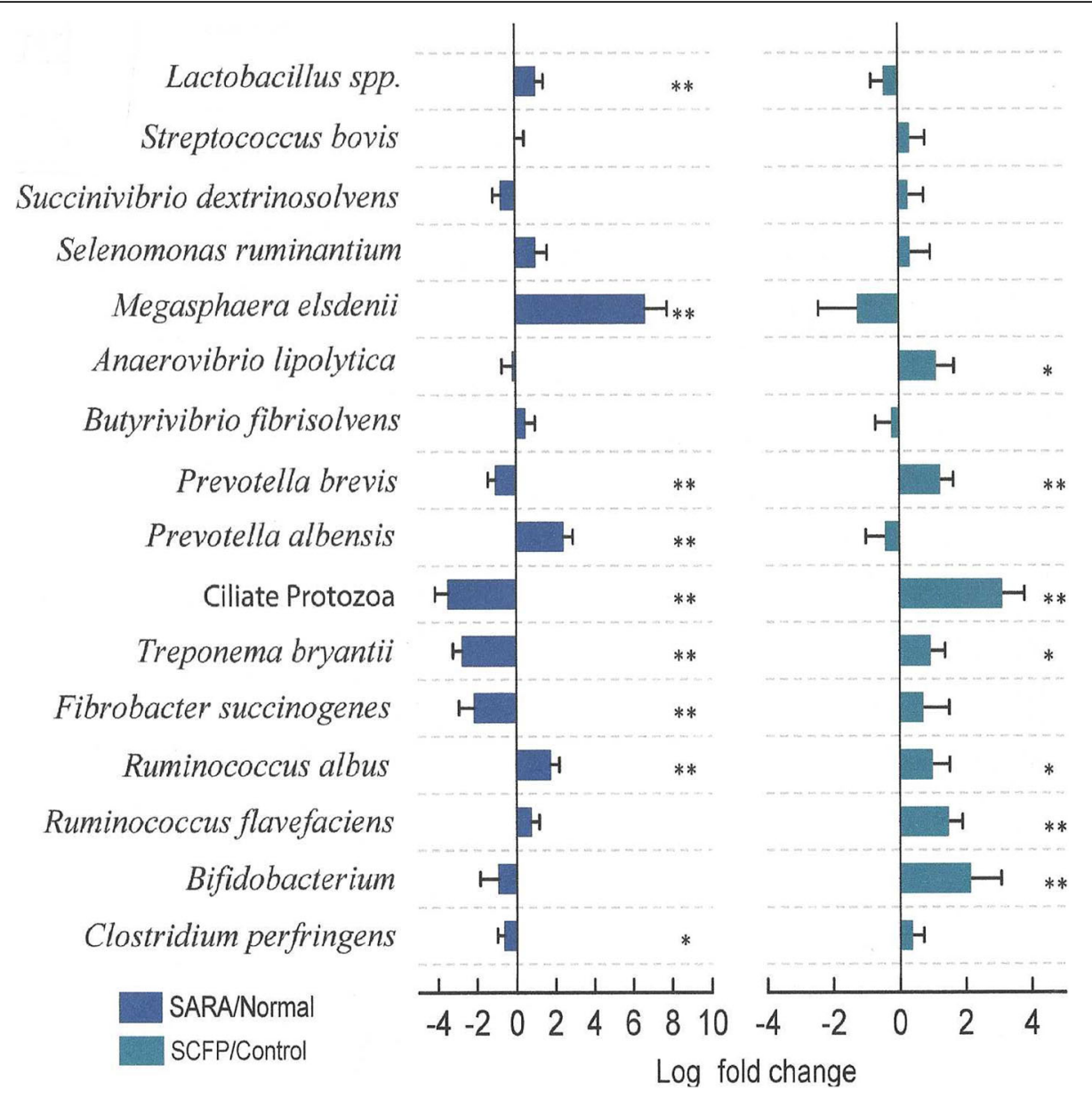

Fig. 3 Effect of SCFP treatment and SARA challenge on the abundances of selected ruminal microorganisms, determined in vivo by qPCR. No interaction was detected; therefore, data was presented separately by SCFP treatment and SARA treatment. Comparisons are made SARA challenge vs. Normal Feeding and SCFP supplementation vs. no SCFP supplementation, ${ }^{*}$ represents $P<0.10$; ${ }^{* *}$ represents $P<0.05$

Panibacillaceae and Spirochaetaceae were reduced by SARA challenge, but these reductions were alleviated by SCFP $(P<0.05)$. In contrast, the abundance of Methanobacteria and unclassified Euryarchaeota increased during the SARA challenge in cows that did not receive SCFP, whereas it decreased in cows that were supplemented with SCFP. Figure 7 shows that genes encoding for FDH and MCM increased due to SCFP supplementation during the SARA challenge, but not in the absence of SARA.

\section{Discussion}

\section{SARA challenge}

In order to conduct the SARA challenge, the dietary fibre content was reduced and that of starch increased. Hence, it was expected that this challenge would reduce abundances of fibrolytic and $\mathrm{pH}$ sensitive bacteria and increase those of amylolytic and $\mathrm{pH}$ tolerant bacteria, as well increase those of bacteria that utilize intermediates of starch fermentation [1, 2, 4]. In a parallel study [9], we showed that, across SCFP treatments, the SARA challenge increased the duration of the $\mathrm{pH}$ below 5.6 and reduced the acetate to propionate ratio in the rumen from 11.1 to $311.1 \mathrm{~min} / \mathrm{d}$, and from 3.07 to 1.74 , respectively. The threshold used for SARA that was used in our study was a rumen $\mathrm{pH}$ depression below 5.6 of $180 \mathrm{~min} /$ $\mathrm{d}[1,2]$. Based on this threshold, SARA was induced successfully. This threshold was developed on the assumption that microbial enzymes and the growth of microorganisms in the rumen are sensitive to this $\mathrm{pH}$ depression, and that a more severe rumen $\mathrm{pH}$ depression increase the concentrations of serum amyloid A (SAA) in peripheral blood plasma and lipopolysaccharide endotoxin (LPS) in rumen fluid $[1,4]$. In agreement, the parallel study also showed that, in the absence of SCFP supplementation, the SARA challenge increased the concentrations of SAA from 72.5 to $209.9 \mu \mathrm{g} / \mathrm{mL}$ and that of rumen LPS from 15,389 to $123,296 \mathrm{EU} / \mathrm{mL}$. This endotoxin is shed by gram-negative bacteria, and can cause inflammation and disruption of the barrier function of the rumen epithelium $[1,4]$. Hence, this increase 
Table 3 Relative abundances of rumen microbial domains and phyla affected by Saccharomyces cerevisiae fermentation products (SCFP) supplementation and a subacute ruminal acidosis (SARA) challenge as determined by shotgun metagenomic-based analysis

\begin{tabular}{|c|c|c|c|c|c|c|c|c|}
\hline \multirow[t]{2}{*}{ Item } & \multicolumn{2}{|l|}{ No SCFP } & \multicolumn{2}{|l|}{ SCFP } & \multirow[t]{2}{*}{$\mathrm{SEM}^{1}$} & \multirow[b]{2}{*}{ SARA } & \multicolumn{2}{|c|}{ P-value } \\
\hline & Control & SARA & Control & SARA & & & SCFP & SARA *SCFP \\
\hline Archaea & $0.71^{y}$ & $1.15^{x}$ & $1.80^{x}$ & $0.70^{y}$ & 0.14 & 0.07 & 0.07 & $<0.01$ \\
\hline Euryarchaeota & 0.95 & 1.02 & $1.69 a$ & $0.92 b$ & 0.19 & 0.02 & 0.02 & $<0.01$ \\
\hline Bacteria & 98.36 & 97.52 & 97.05 & 97.36 & 0.7 & 0.72 & 0.34 & 0.42 \\
\hline Actinobacteria & 3.89 & 6.76 & 11.13 & 6.82 & 2.15 & 0.74 & 0.10 & 0.11 \\
\hline Bacteroidetes & 42.06 & 36.51 & 34.59 & 40.2 & 4.49 & 0.99 & 0.68 & 0.22 \\
\hline Chlorobi & 0 & 0.03 & 0 & 0 & 0 & 0.14 & 0.14 & 0.14 \\
\hline Fibrobacteres & $0.69^{\mathrm{a}}$ & $0.19^{b}$ & $0.59^{\mathrm{a}}$ & $0.35^{b}$ & 0.14 & 0.01 & 0.82 & 0.35 \\
\hline Firmicutes & $36.9^{y}$ & $46.49^{x}$ & $38.25^{y}$ & $42.01^{x}$ & 3.78 & 0.09 & 0.68 & 0.45 \\
\hline Fusobacteria & 0.02 & 0 & 0 & 0 & 0.01 & 0.33 & 0.33 & 0.33 \\
\hline Nitrospirae & 0.05 & 0.01 & 0.02 & 0 & 0.02 & 0.12 & 0.35 & 0.75 \\
\hline Planctomycetes & $0.14^{x}$ & $0.05^{y}$ & $0.2^{x}$ & $0.11^{y}$ & 0.04 & 0.06 & 0.18 & 1 \\
\hline Proteobacteria & 1.89 & 1.45 & 2 & 1.29 & 0.35 & 0.11 & 0.94 & 0.7 \\
\hline Spirochaetes & $4.67^{\mathrm{a}}$ & $1.52^{b}$ & $3.52^{\mathrm{a}}$ & $1.86^{\mathrm{b}}$ & 0.64 & $<0.01$ & 0.53 & 0.25 \\
\hline Synergistetes & 0.01 & 0 & 0 & 0.01 & 0.01 & 1 & 1 & 0.18 \\
\hline Tenericutes & $5.06^{\mathrm{a}}$ & $2.95^{b}$ & $4.4^{\mathrm{a}}$ & $2.14^{b}$ & 0.51 & $<0.01$ & 0.16 & 0.88 \\
\hline Verrucomicrobia & $0.16^{\mathrm{a}}$ & $0^{b}$ & $0.15^{b}$ & $0.01^{b}$ & 0.05 & $<0.01$ & 1 & 0.8 \\
\hline Unclassified & 1.42 & 1.31 & 1.27 & 2.36 & 0.37 & 0.2 & 0.24 & 0.12 \\
\hline Eukaryota & 0.41 & 0.4 & 0.26 & 1.15 & 0.46 & 0.18 & 0.93 & 0.16 \\
\hline Chlorophyta & 0.04 & 0.01 & 0.02 & 0 & 0.02 & 0.21 & 0.52 & 1 \\
\hline Streptophyta & 0.1 & 0.14 & 0.05 & 0.29 & 0.1 & 0.18 & 0.62 & 0.33 \\
\hline Unclassified & 0.11 & 0.02 & 0.41 & 0.15 & 0.19 & 0.37 & 0.28 & 0.65 \\
\hline
\end{tabular}

${ }^{1}$ SEM standard error of mean

a, b LSmeans with different letters within SCFP treatment (No SCFP or SCFP) differ $(P<0.05)$

$x, y$ LSmeans with different letters within SCFP treatment (No SCFP or SCFP) tend to differ $(P<0.10)$

in rumen LPS is additional evidence of the adverse effects of the SARA challenge on rumen bacteria.

The observed reductions in the microbial richness and diversity in the rumen during the SARA challenge agree with earlier research that shows that SARA compromises the functionality of the rumen microbiota $[3,10,11]$. Also, in agreement with previous studies [3, 10, 11], our gene sequencing data demonstrated that Bacteroidetes, Firmicutes and Proteobacteria were the dominant ruminal phyla. Members of the Bacteroidetes phyla are considered more efficient fermenters of complex polysaccharides, compared to Firmicutes, and thus, represent the primary degraders for these compounds in the rumen [12]. As such the reduction in the relative abundance of Bacteroidetes during the SARA challenge may be undesirable. Reductions in this abundance of Bacteroidetes and increases in the relative abundances of Firmicutes and Proteobacteria due to excessive grain feeding and grain-based SARA challenges have been reported previously [3, 13]. However, in contrast to earlier studies, our gene sequencing data did not show that the SARA challenge increased the relative abundances of Firmicutes [3, 10, 14] and Proteobacteria [15]. However, in contrast with our findings and using a similar sequencing technology, Fernando et al. [14] observed that switching cows from a low grain to a high grain diet increased the relative abundance of Bacteroidetes, but did not affect that of Proteobacteria. These discrepancies among studies may result from differences in the amount of dietary grain, and therefore starch, in the control and high grain treatments, as large differences between these treatments may result in larger responses. Responses to such increases also vary among cows. This was shown by Khafipour et al. [15], who demonstrated that a large increase in grain feeding increased the relative abundance of Firmicutes in the rumen in cows that responded severely to a grain-based SARA challenge, but not in cows that responded moderately to this challenge.

The ordination plots of the microbiome beta-diversity based on 16S rRNA gene sequencing and shotgun metagenomics also demonstrated that the SARA challenge affected the microbiological beta-diversity of the rumen. 


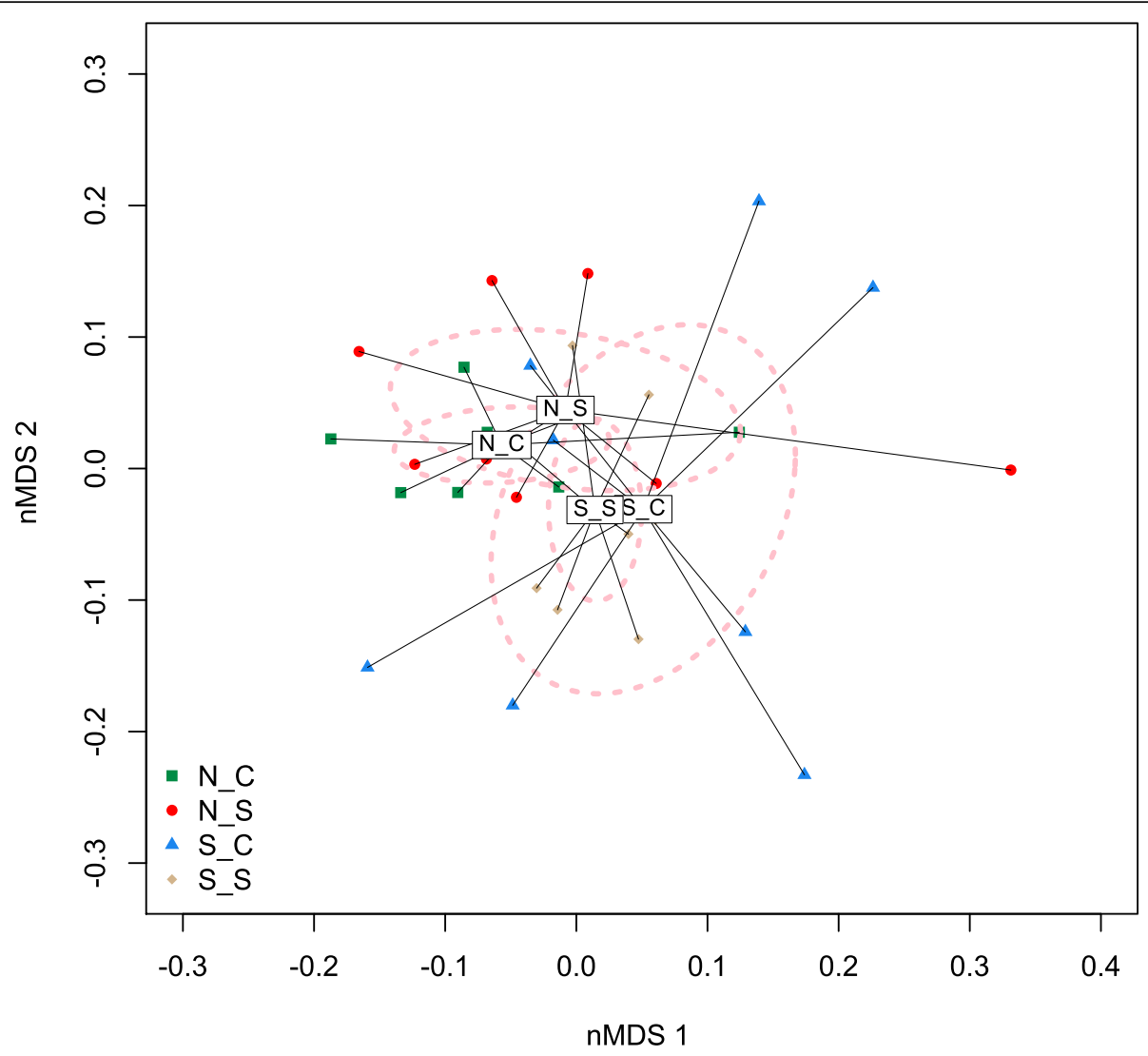

Fig. 4 nMDS plot based on Bray-Curtis distance matrix illustrates variation in rumen bacterial communities affected by subacute ruminal acidosis (SARA) challenge and supplementation of Saccharomyces cerevisiae fermentation products (SCFP) from shotgun metagenomic sequencing. The significance of the effects of SARA challenge, SCFP supplementation and their interaction were $P<0.05, P<0.05$, and $P<0.42$, respectively. Abbreviations in the figure: N_C, normal diet without SCFP supplementation; N_S, normal diet with SCFP supplementation; S_C, SARA challenge without SCFP supplementation; S_S, SARA challenge with SCFP supplementation

The effects of the SARA challenge on the abundances of bacterial phyla determined with shotgun metagenomics differed from that determined by $16 \mathrm{~S}$ rRNA gene sequencing. In contrast to the $16 \mathrm{~S}$ rRNA gene sequencing data, the metagenomic data did not show effects of the SARA challenge, the SCFP treatment and their interaction on the abundances of Bacteroidetes or Proteobacteria. These discrepancies between methods may be due to differences in sequencing targets, biases and coverage, including unequal amplification of species' 16S rRNA genes, insufficient depth of metagenomic sequencing for the identification of low abundance species, and insufficient taxa-specific microbial reference genome sequences between the techniques [16-18]. As a result, Shah et al. [16] recommended that, until sufficient reference sequences are available, metagenomic shotgun analysis needs to be combined with $16 \mathrm{~S}$ rRNA gene sequencing to obtain sufficient accuracy on the effects of dietary treatments on the composition of gut microbiota.

In the rumen, Bacteroidales and Prevotella were the most abundant taxa within Bacteroidetes and several genera within Ruminococcaceae were the most abundant genera within Firmicutes, which agrees with previous studies $[3,10,13]$. The proportion of the rumen genera affected by the SARA challenge was higher in our study than that in earlier studies, and there is no agreement among studies on which genera are the most affected by a SARA challenge [10, 11]. Reasons for this discrepancy may be that the rumen $\mathrm{pH}$ depression in our study was greater than in previous studies, and that the response of rumen genera to grain challenge is highly variable. Nevertheless, our study and earlier studies agree that the number of genera affected by SARA challenges is limited.

Our study, as well as earlier studies using qPCR, agree that SARA challenges affect the populations of many species of rumen bacteria. Whereas in agreement with previous studies $[3,10,13]$, the SARA challenge increased the populations of starch and sugar utilizing bacteria, this challenge only reduced the populations of fibrolytic bacteria in the absence of SCFP. The reduction in the populations of fibrolytic bacteria in the absence of 


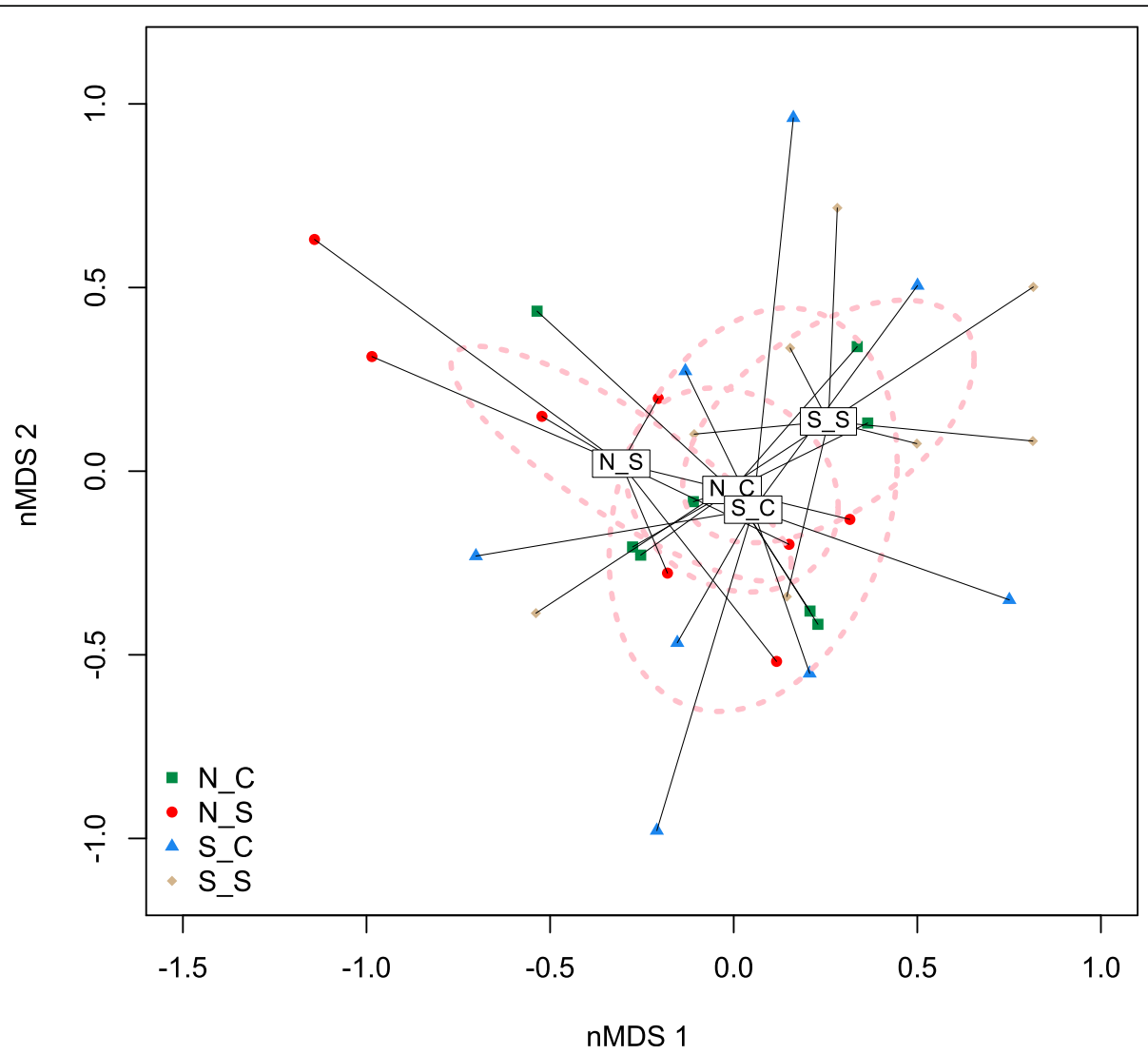

Fig. 5 nMDS plot based on Bray-Curtis distance matrix of ruminal microbiome functions illustrates the effect of subacute ruminal acidosis (SARA) challenge and Saccharomyces cerevisiae fermentation products (SCFP) supplementation from shotgun metagenomic sequencing. The effects of SARA challenge, SCFP supplementation and their interaction were significant $(P<0.05)$. Abbreviations in figure: N_C, normal diet without SCFP supplementation; N_S, normal diet with SCFP supplementation; S_C, SARA challenge without SCFP supplementation; S_S, SARA challenge with SCFP supplementation.

SCFP agrees with earlier studies [3, 13, 15]. Hence, at the species level, the changes in the size of these populations appear to reflect changes in available substrates. However, as rumen bacteria compete for substrates and share functionality, assessing the populations of only a selected few species of rumen bacteria may not provide a comprehensive overview of changes in the species composition of rumen microbiota [10, 11, 19].

The analysis of the relative abundances of metabolic functions by shotgun metagenomic sequencing showed that the SARA challenge increased or tended to increase protein metabolism $(P=0.08)$, and metabolism of aromatic compounds $(P=0.04)$. The challenge tended to decrease nitrogen metabolism $(P<0.1)$ and increased sulphur metabolism $(P<0.05)$ in the absence of SCFP supplementation. In the rumen, nitrogen metabolism primarily involves microbial proteolytic activity [20,21]. The challenge only decreased phosphorus metabolism $(P<0.05)$ when SCFP were supplemented. This activity of proteolytic microbes depends on the chemical structure of dietary proteins, the rumen $\mathrm{pH}$, and the predominant proteolytic species of bacteria present in the rumen [21]. Thus, the influence of the SARA challenge on nitrogen metabolism in the rumen may be a consequence of changes in the abundance of proteolytic bacteria, which may be driven by a reduction of the rumen $\mathrm{pH}[2]$.

The impact of the reductions in the abundances of Paenibacillaceae and Spirochaetaceae by the SARA challenge is unclear. The family Spirochaetaceae is associated with diseases in ruminants with the rumen and feces being considered a reservoir for these microbes [22]. The family Paenibacillaceae are organoheterotrophic, and utilize carbohydrates as well as amino acids [23].

The reductions of the abundances of the genes coding for the enzymes MCM and FDH that resulted from the SARA challenge may impair the functionality of rumen microbiota. The enzyme FDH catalyzes the oxidation of formate to $\mathrm{CO}_{2}$, and has been found in bacteria [17] and hydrogenotrophic methanogenic archaea [24]. As a result, many species of these archaea utilize formate instead of $\mathrm{H}_{2}$. A reduced expression of FDH may, 
Table 4 Relative abundances of metabolic functions (based on subsystem annotation) as determined by shotgun metagenomic sequencing of the rumen microbiome as affected by Saccharomyces cerevisiae fermentation products (SCFP) supplementation and a subacute ruminal acidosis (SARA) challenge

\begin{tabular}{|c|c|c|c|c|c|c|c|c|}
\hline \multirow[t]{2}{*}{ Item } & \multicolumn{2}{|l|}{ No SCFP } & \multicolumn{2}{|l|}{ SCFP } & \multirow[t]{2}{*}{ SEM } & \multirow[b]{2}{*}{ SARA } & \multicolumn{2}{|c|}{ P-value } \\
\hline & Control & SARA & Control & SARA & & & SCFP & SARA *SCFP \\
\hline Amino Acids and Derivatives & 9.78 & 12.44 & 8.14 & 7.94 & 1.95 & 0.53 & 0.13 & 0.47 \\
\hline Carbohydrates & 13.11 & 12.44 & 17.17 & 14.24 & 1.78 & 0.32 & 0.11 & 0.53 \\
\hline Cell Division and Cell Cycle & 0.23 & 0.2 & 0.26 & 0.34 & 0.12 & 0.84 & 0.49 & 0.62 \\
\hline Cell Wall and Capsule & 7.72 & 4.5 & 4.2 & 5.58 & 1.19 & 0.45 & 0.32 & 0.06 \\
\hline Clustering-based Subsystems & 2.04 & 3.67 & 2.71 & 2.49 & 0.67 & 0.3 & 0.7 & 0.18 \\
\hline Cofactors, Vitamins, Prosthetic Groups, Pigments & 2.52 & 3.5 & 2.98 & 2.8 & 0.5 & 0.43 & 0.81 & 0.25 \\
\hline DNA Metabolism & 1.82 & 1.65 & 1.48 & 1.84 & 0.37 & 0.8 & 0.84 & 0.48 \\
\hline Dormancy and Sporulation & 0.03 & 0.55 & 0.03 & 0.12 & 0.24 & 0.23 & 0.37 & 0.39 \\
\hline Fatty Acids, Lipids, and Isoprenoids & 4.72 & 4.95 & 8.08 & 2.78 & 1.99 & 0.21 & 0.77 & 0.18 \\
\hline Iron Acquisition and Metabolism & 0.34 & 0.57 & 0.79 & 0.34 & 0.22 & 0.62 & 0.64 & 0.13 \\
\hline Membrane Transport & 0.39 & 0.72 & 0.79 & 0.62 & 0.17 & 0.63 & 0.39 & 0.16 \\
\hline Metabolism of Aromatic Compounds & $0.7^{b}$ & $1.24^{\mathrm{a}}$ & $0.58^{\mathrm{b}}$ & $1.48^{\mathrm{a}}$ & 0.03 & 0.04 & 0.86 & 0.59 \\
\hline Miscellaneous & 2.39 & 3.26 & 3.03 & 2.56 & 0.54 & 0.72 & 0.96 & 0.23 \\
\hline Motility and Chemotaxis & 0.08 & 0.25 & 0.13 & 0.51 & 0.18 & 0.13 & 0.39 & 0.57 \\
\hline Nitrogen Metabolism & $1.7^{x}$ & $0.86^{y}$ & 1.18 & 1.39 & 0.26 & 0.24 & 0.99 & 0.06 \\
\hline Nucleosides and Nucleotides & 0.55 & 0.63 & $1.05^{x}$ & $0.37^{y}$ & 0.19 & 0.13 & 0.53 & 0.06 \\
\hline Phages, Prophages, Transposable Elements, Plasmids & 21.64 & 19.52 & 18.61 & 19.13 & 8.53 & 0.88 & 0.8 & 0.92 \\
\hline Phosphorus Metabolism & 0.11 & 0.16 & $0.99^{\mathrm{a}}$ & $0.14^{\mathrm{b}}$ & 0.18 & 0.03 & 0.02 & 0.02 \\
\hline Photosynthesis & $0.11^{\mathrm{b}}$ & $0.18^{\mathrm{a}}$ & $0.09^{b}$ & $0.19^{\mathrm{a}}$ & 0.03 & 0.01 & 0.91 & 0.64 \\
\hline Potassium Metabolism & 0.05 & 0.07 & 0.12 & 0.02 & 0.03 & 0.24 & 0.82 & 0.10 \\
\hline Protein Metabolism & 16.18 & 16.69 & 11.71 & 19.18 & 2.19 & 0.08 & 0.66 & 0.12 \\
\hline Regulation and Cell Signaling & 0.17 & 0.16 & 0.29 & 0.15 & 0.07 & 0.29 & 0.48 & 0.35 \\
\hline Respiration & 6.08 & 4.67 & 5.72 & 7.38 & 0.91 & 0.89 & 0.21 & 0.10 \\
\hline RNA Metabolism & 6.1 & 4.64 & 5.62 & 6.82 & 1.04 & 0.9 & 0.42 & 0.21 \\
\hline Secondary Metabolism & 0.12 & 0.35 & 1.99 & 0.59 & 0.52 & 0.27 & 0.05 & 0.13 \\
\hline Stress Response & 0.23 & 0.52 & 0.75 & 0.59 & 0.16 & 0.66 & 0.08 & 0.18 \\
\hline Sulfur Metabolism & $0.31^{b}$ & $0.93^{\mathrm{a}}$ & 0.54 & 0.44 & 0.17 & 0.15 & 0.47 & 0.05 \\
\hline Virulence, Disease and Defense & 0.76 & 0.68 & 0.97 & 0.96 & 0.23 & 0.86 & 0.31 & 0.88 \\
\hline
\end{tabular}

${ }^{1}$ SEM standard error of mean

a, b LSmeans with different letters within SCFP treatment (No SCFP or SCFP) differ $(P<0.05)$

$x$, y LSmeans with different letters within SCFP treatment (No SCFP or SCFP) tend to differ $(P<0.10)$

therefore, enhance $\mathrm{H}_{2}$ utilization, and, lessen the decline in $\mathrm{pH}$ during a SARA challenge. In contrast, MCM catalyzes the conversion of methylmalonyl-CoA to succinylCoA, and is therefore, part of key metabolic pathways [25]. In humans, it is the first vitamin B12-depedent enzyme, and a deprivation of its activity results in metabolic acidosis and methylmalonic acidemia [26]. Little is known about the role of this enzyme in ruminants, but due to its critical role in metabolism, a reduced expression of the MCM gene may be considered adverse.

The SARA challenges resulted in many changes in the composition and predicted functionality of the rumen microbiota. However, it is difficult to conclude if these changes are normal adaptations to a higher grain diet, or if these changes affect the health of dairy cows adversely. However, as SARA challenges reduce feed intake, fibre digestion, and milk fat production, and increase in bacterial endotoxins in rumen digesta and blood plasma, as well as markers of inflammation $[1,4,10]$, it may be assumed that, overall, these changes of the rumen microbiota are adverse.

\section{SCFP treatment}

In both the in vitro and the in vivo trial, the qPCR data demonstrated that SCFP increased the populations of major fibrolytic and amylolytic bacteria, suggesting that 


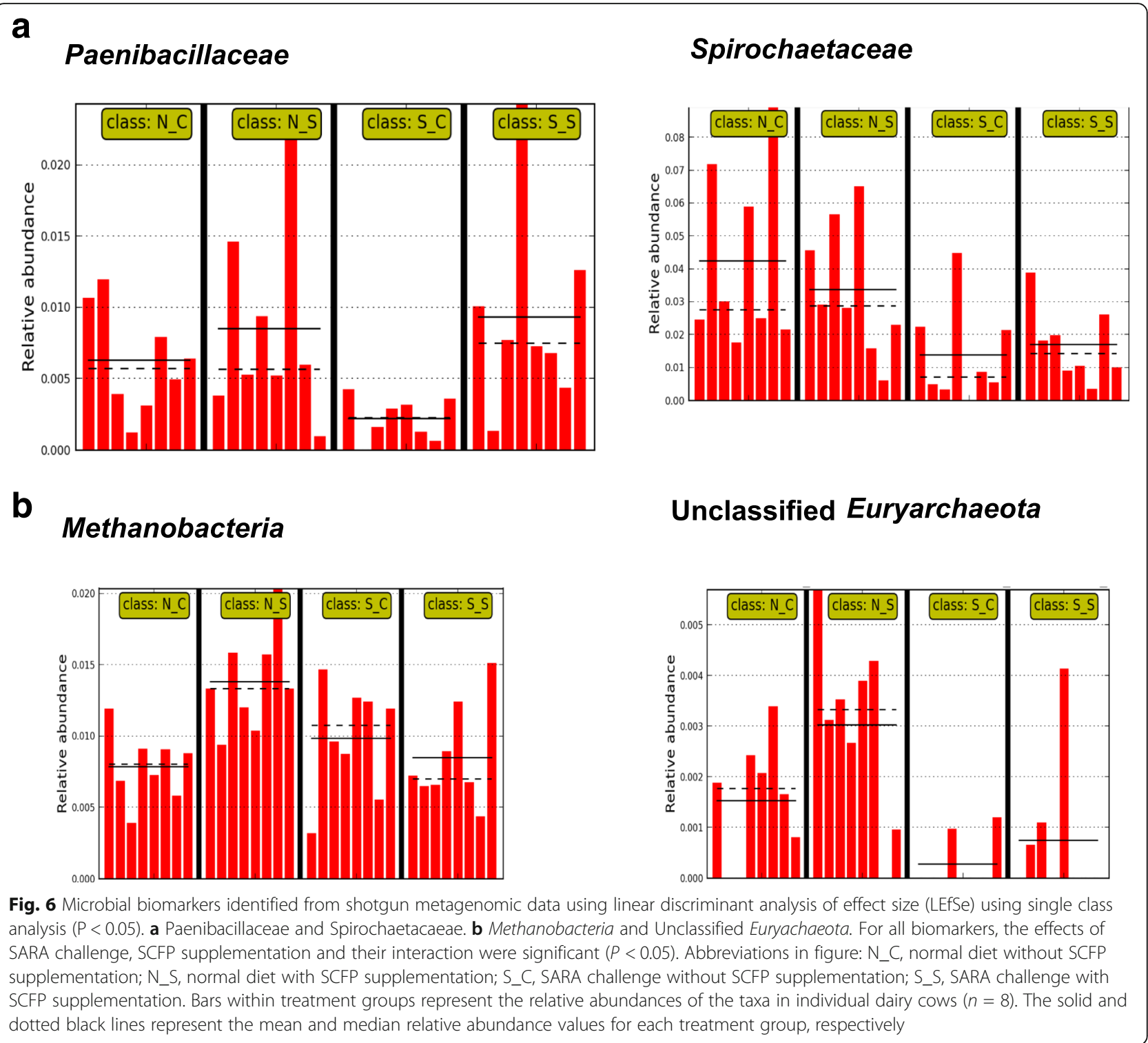

the supplementation of SCFP is beneficial to the utilization of carbohydrates in the rumen [2]. In the in vivo trial, the populations of $F$. succinongenes and $R$. flavefaciens increased more under the depressed $\mathrm{pH}$ than under the high $\mathrm{pH}$, which is beneficial as the populations of these bacteria are reduced by high grain feeding $[3,10,13]$. However, the increases in F. succinogenes, and M. elsdenii observed in vitro, were not evident in vivo. These discrepancies may have been due to the higher concentrations of cellulolytic bacteria and lower protozoal concentrations in the in vitro study. Despite the similarity of the qPCR method that was used, our in vivo qPCR results differ from those of Mullins et al. [18], as these authors did not observe effects of SCFP supplementation on the populations of selected species and genera of rumen microbiota. These authors suggested that the lack of these effects may be due to the incomplete coverage of the rumen microbiota by their qPCR analysis, and that the functionality, rather than the taxonomic composition of rumen microbiota, was altered by the SCFP supplementation. Other reasons for this discrepancy may include differences in the main grain source between the studies. Whereas dry-rolled barley grain was used in our study, high moisture corn was the main grain source in the earlier study. The higher rumen degradability of high moisture corn compared to dry-rolled barley grain may have resulted in differences in the rumen environment between these studies. This discrepancy highlights that factors other than the dietary starch content affect the taxonomic composition of rumen microbiota as determined by qPCR. 

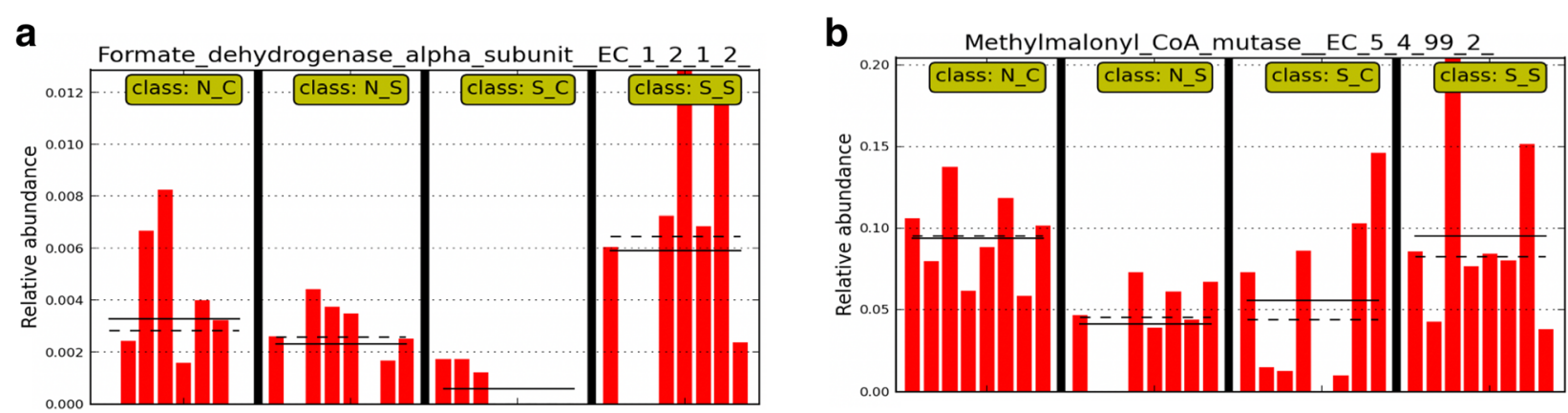

Fig. 7 Microbial metabolic functions (a) formate dehydrogenase alpha (FDH) subunit EC.1.2.1.2 and (b) methylmalonyl CoA mutase EC.5.4.99.2, based on subsystem annotation as affected by SCFP supplementation during the SARA challenge (single class LEfSe, $P<0.05)$. For both enzymes, the effects of SARA challenge, SCFP supplementation and their interaction were significant $(P<0.05)$. Abbreviations in figure: $N \_C$, normal diet without SCFP supplementation; N_S, normal diet with SCFP supplementation; S_C, SARA challenge without SCFP supplementation; S_S, SARA challenge with SCFP supplementation. Bars within treatment groups represent the relative abundances of the enzyme in individual dairy cows ( $n$ = 8). The solid and dotted black lines represent the mean and median relative abundance values for each treatment group, respectively

Our in vivo qPCR data also showed that SCFP supplementation increased the populations of Bifidobacterium spp. and ciliate protozoa. Bifidobacterium possess unique pathways to ferment non-structural carbohydrates [27]. Hence, an increase in the population of these bacteria will enhance rumen fermentation, especially when high-grain diets are fed. Protozoa stabilize the rumen environment by modulating bacterial metabolism and reducing the rate of fermentation of starch [28]. Hence, the attenuation of the SARA-induced reduction of the population of ciliate protozoa in the rumen due to supplementation with SCFP benefits rumen function during high grain feeding.

Many results of our study showed that the impacts of the SARA challenge on the composition and functionality of rumen microbiota were attenuated by the supplementation with SCFP. These effects of SCFP include limiting the SARA-induced reductions in the richness and diversity and the changes in the beta-diversity of rumen microbiota. Members of the rumen microbiota vary in their preferred substrates and functionality [29]. Hence, a larger richness and diversity of rumen microbiota allows more efficient use of resources under different conditions, including during nutritional challenges $[2,3,29]$. Hence, the limitation of the SARA-related drop of the richness and diversity of the rumen microbiota due to SCFP supplementation is beneficial to the health and production of the host cows.

Despite of the SARA-mitigating effects of SCFP, including effects on the abundances of several species of rumen bacteria, this supplementation only reduced the impact of SARA on one bacterial phylum, i.e. Bacteroidites, and one bacterial genus, i.e. unclassified Bacteriodales. Also, the abundance of only one genus, i.e. other Firmicutes, tended to be increased by SCFP supplementation. This raises the question why SCFP supplementation has so many more effects on the species than on the phylum and genus levels. This may, as suggested by Mullins et al. [18] be due to an incomplete coverage of the rumen microbiota in the qPCR, analysis, but other differences between $\mathrm{qPCR}$ and $16 \mathrm{~S}$ rRNA sequencing may also play a role. Hence, it would be beneficial to confirm the qPCR results with $16 \mathrm{~S}$ rRNA sequencing, but unfortunately the latter technique is currently not sufficient accurate for taxa identification at the species level.

Our results at the genus level, also contrasts recent findings that reported a decline in Prevotella and an increase in Butyrivibrio with SCFP supplementation in calves [30]. Yet, despite the proteolytic activity of Prevotella and butyrate producing activity of Butyrivibrio, no differences in the rumen concentrations of VFA were observed due to SCFP supplementation in their study and in our parallel study [9]. The discrepancy could possibly be driven by differing primers between the two sequencing studies (V1-V3 compared to V3, respectively), animal age and basal diet, as the calves were still receiving a milk-based diet in the study of Xiao et al. [30].

At the microbial functionality level, our shotgun metagenomic analysis showed that, in the absence of SCFP, the potential metabolisms of phosphorus and sulphur increased and that of nitrogen tended to decrease during the SARA challenge. This decrease in nitrogen metabolism may be related to a reduced proteolytic activity from rumen microbiota [31, 32]. The effects of increases in phosphorus and sulphur metabolism in the rumen translated to changes in functionalities at the level of the host cow. However, as most changes in functionalities resulting from the SARA affect the production and health of cows negatively, it may be assumed that these changes in microbiome functionalities are adverse, and that the 
SCFP mitigating effects on these functionalities are, therefore, beneficial.

Supplementation with SCFP only increased the abundances of genes encoding for $\mathrm{FDH}$ and $\mathrm{MCM}$ during the SARA challenge. Increased expression of FDH may, therefore, enhance $\mathrm{H}_{2}$ utilization, and, potentially lessen the decline in pH during a SARA challenge [24]. Little is known about the role of MCM in ruminants, but due to its critical role in metabolism, an increased expression of the MCM gene may be considered beneficial to cows [25].

The reductions in the abundances of Paenibacillaceae and Spirochaetaceae caused by the SARA challenge were also attenuated by SCFP supplementation. The impact of the SARA-mitigating effects of SCFP on the abundances of these families is unclear. Supplementation with SCFP also reduced the abundances of Methanobacteria and unclassified Euryarchaeota during the SARA challenge, but increased these abundances in the absence of SARA. As these taxa include methanogens [24], their reduction has the potential to enhance the energetic efficiency of ruminal fermentation.

\section{Conclusions}

Our study has shown that grain-based SARA challenges reduce the richness, diversity, relative abundance of Bacteroidetes, and that of populations of several fibrolytic bacteria and protozoa. The challenge also increased the relative abundance of Firmicutes, the Firmicutes to Bacteroidetes ratio, and populations of several amylolytic bacteria, and altered the functionality of the ruminal microbiome as determined by shotgun metagenomics. These changes reduce the health and production of dairy cows. Supplementation with SCFP reduced several effects of the SARA challenges by increasing the populations of major fibrolytic and amylolytic bacteria, ciliate protozoa, and Bifidobacterium spp., by attenuating the SARA-related reductions of the richness and diversity of rumen microbiota, by increasing the abundances of genes encoding for important enzymes, and possibly by increasing the energetic efficiency of rumen fermentation. This supplementation also affected the functionality of the rumen microbiota, but the impact of these effects on the health and production of the host cows is not clear. Overall, our results show that supplementation with SCFP) stabilize the ruminal microbiota of lactating dairy cows during periods of a depressed rumen $\mathrm{pH}$.

\section{Methods}

\section{In vitro study}

This study comprised of one run at a high $\mathrm{pH}(>6.3)$ and two runs at a low $\mathrm{pH}(5.8-6.0)$. Rumen fluid from two non-lactating cows fed a 50:50 mixture of forage and concentrate diet was collected, pooled and immediately moved to an anaerobic chamber. The rumen fluid was filtered through four layers of cheesecloth and buffered to $5 \%$ with a buffer containing $8.2 \mathrm{mM} \mathrm{NaCl}, 3.63$ $\mathrm{mM}\left(\mathrm{NH}_{4}\right)_{2} \mathrm{SO}_{4}, 40 \mathrm{mM} \mathrm{K \textrm {H } _ { 2 }} \mathrm{PO}_{4}, 0.5 \mathrm{mM} \mathrm{CaCl}-2 \mathrm{H}_{2} \mathrm{O}$, $0.5 \mathrm{mM} \mathrm{MgSO}_{4}-7 \mathrm{H}_{2} \mathrm{O}, 0.004 \mathrm{mM}$ Resazurin, and 110 $\mathrm{mM} \mathrm{NaHCO} 3$ [31]. For the neutral pH, $50 \mathrm{~mL}$ conical tubes containing commercial SCFP products $(0.05 \mathrm{~g}$ XPC or 0.07 g NutriTek; Diamond V, Cedar Rapids, IA) and substrate (50:50 total mixed ration) were filled with $30 \mathrm{~mL}$ of buffered rumen fluid and incubated at $37^{\circ} \mathrm{C}$ for $12 \mathrm{~h}$ during continuous mixing. The low $\mathrm{pH}$ experiment was performed with the buffer containing $50 \%$ of the $\mathrm{NaHCO}_{3}$ and substrate amount 2.5-fold higher than that of the neutral $\mathrm{pH}$ experiment. Within each run, treatments were run in quintuplet. After fermentation, tube contents were spun down at 15,000 $\times g$ for $10 \mathrm{~min}$ and the pellets were subjected to DNA extraction and qPCR.

\section{In vivo study}

Cows were housed in individual stalls in the large animal metabolism facility of the Glenlea Research Station, University of Manitoba, MB, Canada. Cows were fed ad libitum at 9:00 and had unlimited access to fresh water. All procedures and handing were approved by the Fort Garry Campus Animal Care Committee in accordance with the Canadian Council for Animal Care guidelines [32]. At the end of the study, the cows returned to the dairy herd of the research station.

The details of the in vivo study were described previously Li et al. [9]. Briefly, eight lactating, rumen cannulated Holstein cows between $65 \pm 16$ days in milk (mean $\pm \mathrm{SD}$ ) and $605 \pm 60 \mathrm{~kg}$ of body weight were obtained from the dairy herd of the University of Manitoba and returned to this herd after the completion of the study. Cows were blocked based on their parity (primiparous vs. multiparous) and within block randomly assigned to one of two dietary treatments: (1) a basal diet plus $14 \mathrm{~g} / \mathrm{d}$ of $S$. cerevisiae fermentation products (SCFP, Original XPC, Diamond V, Cedar Rapids, IA) mixed with $126 \mathrm{~g} / \mathrm{d}$ ground corn, or (2) a basal diet plus $140 \mathrm{~g} / \mathrm{d}$ ground corn only (Control). The SCFP additive was supplemented as a top dress once daily immediately after feed delivery at 9:00. Experimental periods consisted of 4 weeks of feeding a basal diet followed by a one-week grain-based SARA challenge. The basal diet contained $160 \mathrm{~g} / \mathrm{kg}$ crude protein, $372 \mathrm{~g} / \mathrm{kg}$ neutral detergent fibre, and $153 \mathrm{~g} / \mathrm{kg}$ starch on a dry matter basis. The SARA challenge was conducted by replacing $208 \mathrm{~g} /$ $\mathrm{kg}$ of the control diet with pellets of ground wheat and barley $(50: 50 \mathrm{w} / \mathrm{w})$, and resulted in a diet that contained $183 \mathrm{~g} / \mathrm{kg}$ crude protein, $259 \mathrm{~g} / \mathrm{kg}$ neutral detergent fiber and $222 \mathrm{~g} / \mathrm{kg}$ of starch on a DM basis. Experimental periods were separated by a two-week washout period, 
during which the control diet was fed and no SCFP was supplemented.

Rumen fluid was sampled at $6 \mathrm{~h}$ after feed delivery on the second and fourth day of week 4 and 5 of each experimental period by collecting approximately $500 \mathrm{~mL}$ of rumen fluid from the ventral sac through the cannula. Samples were mixed thoroughly, strained through four layers of cheesecloth, snap-frozen in liquid nitrogen and stored at $-80^{\circ} \mathrm{C}$ until further analysis, as described by Li et al. [9].

\section{DNA extraction}

Prior to DNA extraction, rumen fluid samples were thawed at room temperature and kept on ice. Subsequently, $1 \mathrm{~mL}$ of sample was centrifuged at $15000 \times g$ for $20 \mathrm{~min}$, and the supernatant was removed without disturbing the sediment. Genomic DNA (gDNA) was extracted from the sediment using a ZR fecal DNA kit (Zymo Research Corp., Orange, CA, USA) that included a bead-beating step for the mechanical lysis of the microbial cells. The concentration and purity of isolated gDNA were determined using a NanoDrop 2000 spectrophotometer (ThermoFisher Scientific, Wilmington, DE, USA). DNA samples were then normalized to a final concentration of $20 \mathrm{ng} / \mu \mathrm{L}$ for sequencing and $2 \mathrm{ng} / \mu \mathrm{L}$ for qPCR.

\section{Pyrosequencing}

Rumen DNA was pyrosequenced at the Research and Testing Laboratory (Lubbock, TX; http://www.Researchtesting.com) using the bacterial tag-encoded GS FLXTitanium amplicon sequencing as described by $\mathrm{Pu}$ et al. [33]. Briefly, a mixture of Hot Start, HotStar high fidelity Taq polymerases, and Titanium reagents were used to perform a one-step PCR (35 cycles) with primer $28 \mathrm{f}$ ( $5^{\prime}$ GAGTTTGATCNTGGCTCAG-3') and 519r (5'GTNTTACNGCGGCKGCTG-3'), which covered the variable regions V1-V3 of the bacterial 16S rRNA genes.

\section{Shotgun metagenomic library construction and sequencing}

A total of $50 \mathrm{ng}$ of extracted DNA from each sample was used to construct a shotgun metagenomic library using Nextera DNA Library Preparation kits according to the manufacturer's protocol (Illumina, San Diego, CA, USA). Briefly, DNA was tagmented by the Nextera transposome, cleaned and the purified tagmented DNA was amplified in 5 cycle PCR program to add index 1 and 2, and common adapters P5 and P7 for multiplexing. Subsequently, the library was purified using AMPure XP beads (Beckman Coulter Genomics, Danvers, MA, USA) providing a size selection to remove short library fragments. The purified library was quantified using high sensitivity Qubit assays (Fisher Scientific, Ottawa, ON,
Canada), and quality controlled to check the size distribution using high sensitivity Bioanalyses assays (Aglient Technologies, Santa Clara, CA, USA). Equal concentrations of four shotgun libraries were pooled for a sequencing run. Based on the size distribution, DNA concentrations for a pooled library was calculated for expected cluster generation as recommended by Illumina and subjected for $300 \mathrm{bp}$ paired-end sequencing on a Miseq platform (Illumina, San Diego, CA, USA) at the Gut Microbiome Laboratory, University of Manitoba, Winnipeg, Canada. All sequencing data were deposited into the European Nucleotide Archive (ENA) (http:// www.ebi.ac.uk/ena) of European Molecular Biology Laboratory-European Bioinformatic Institute (EMBLEBI) and can be accessed via accession number ERP117106.

\section{Bioinformatics analyses}

Sequencing data were assigned to their respective samples using associated bar code sequences, and filtered using the default parameters in QIIME version 1.9 [34]. All sequences shorter than $200 \mathrm{bp}$, those containing any ambiguous nucleotide bases and/or a homopolymer length greater than $7 \mathrm{bp}$ were removed from the dataset. Chimeric sequences were detected and removed using the UCHIME algorithm (USEARCH 6.1) with the Greengenes gold database as a reference [35]. An open reference-based OTU picking approach was implemented using the QIIME algorithm and the Usearch61 method46, with default parameters to cluster the sequences at the $97 \%$ sequence similarity level using the Greengenes database (v13.5) [36]. Sequences that failed to cluster were subsampled for de novo OTU picking. All picked OTUs were subsequently aligned by PyNAST [37], and a phylogenetic tree was built using the FastTree method [38] to calculate UniFrac distances within QIIME [39]. Taxonomy was assigned to OTUs using RDP classifiers via QIIME with a confidence threshold of 0.8 [40].

The phylogenetic tree was built after it was rooted based on an artificially added archaea outgroup into the data set. Subsequently the OTU table was generated by QIIME, and the mapping file was assembled into a Phyloseq object [41]. The same sequencing depth for all samples was used for alpha-diversity analysis and betadiversity analysis using Phyloseq [42]. Standard alphadiversity metrics were evaluated, including the Observed Richness, Shannon index, and Simpson index. In terms of beta-diversity analysis, UniFrac-based principal coordinates analysis (PCoA) as well as nonmetric multidimensional scaling (nMDS) plots using Bray-Curtis distance were conducted with Phyloseq. Permutational multivariate analyses of variance (PERMANOVA) [41] based on the same similarity matrix were used to test 
the effect of the SARA challenges, SCFP supplementation and their interaction on the beta-diversity of rumen bacterial communities.

\section{Shotgun metagenomic analysis}

In total, 103.4 GB sequences were obtained from 32 shotgun metagenomic samples with an average of $10 \mathrm{M}$ sequences per sample. Data analysis was carried out as previously described [43] with some modifications. Briefly, host genomic sequences were removed from the generated shotgun metagenomic reads using a reference bovine genomic database [44] prior to submission to the MG-RAST pipeline [45] for both taxonomic and functional annotations. Taxonomies were annotated against the Greengenes database and functional genes were annotated against SEED subsystems in the MG-RAST pipeline. For parameter settings in this analysis, a maximum e-value of 0.01 , minimum percent identity of 50 , minimum alignment length of 50 and a raw score maximum of 0.3 were applied. The microbial biomarkers affected by SARA challenge and SCFP treatment were examined using Linear Discriminant Analysis with Effect Size (LEfSe) [46]. This included the non-parametric factorial Kruskal-Wallis sum rank test, followed by linear discriminant analysis (LDA) to estimate the effect size of each differentially abundant feature. Alpha value for the factorial Kruskal-Wallis test was 0.05 and the threshold on the logarithmic LDA score for discriminative features was set at 2.0 , so that features with at least 100 -fold shifts were considered significant. During LEfSe analysis, multiple hypothesis testing for the effects of SARA challenges, SCFP supplementation, and their interaction were conducted based on both single class and multiclass analysis approach.

\section{Quantitative PCR analysis In vitro study}

qPCR was carried out with a CFX96 Real-Time PCR System (BioRad Laboratories, Hercules, CA, USA) using SsoFast EvaGreen Supermix (BioRad Laboratories). Each reaction contained $250 \mathrm{nM}$ primers $(900 \mathrm{nM}$ for Megasphaera elsdenii) (Integrated DNA Technologies, Coralville, IA, USA) $10 \mu \mathrm{L}$ of supermix and $2 \mathrm{ng} / \mathrm{mL}$ of DNA. Primers used for universal bacteria, $F$. succinogenes, $M$. elsdenii, Ruminococcus albus, R. flavefaciens, Selenomonas ruminantium, and Streptococcus bovis are listed in Supplementary Table S1. The two-step amplification conditions were as follows: $98^{\circ} \mathrm{C}$ for $2 \mathrm{~min}$, then $40 \mathrm{cy}-$ cles of $98^{\circ} \mathrm{C}$ for $2 \mathrm{~s}$ and $55^{\circ} \mathrm{C}$ for $5 \mathrm{~s}$.

\section{In vivo study}

qPCR was conducted using an AB 7300 system (Applied Biosystems, Foster City, CA, USA) and the SDS Software (version 1.3; Applied Biosystems, Foster City, CA, USA) as described previously Khafipour et al. [15]. The oligonucleotides were synthesized by University Core DNA Services (University of Calgary, AB, Canada). Each reaction mixture was run in triplicate in a volume of $15 \mu \mathrm{L}$. Amplification reactions were carried out with $7.5 \mu \mathrm{L}$ Power SYBR green PCR master mix (Applied Biosystems, Foster City, CA, USA) mixed with the selected primer set using a final concentration of $450 \mathrm{nM}$. The amplification consisted of one cycle of $95^{\circ} \mathrm{C}(10 \mathrm{~min})$, 40 cycles of denaturation at $95^{\circ} \mathrm{C}(15 \mathrm{~s})$, and annealing/ extension at $60^{\circ} \mathrm{C}(1 \mathrm{~min})$. The only exceptions were for ciliate protozoa, where annealing/extension steps of $63{ }^{\circ} \mathrm{C}(30 \mathrm{~s}) / 72{ }^{\circ} \mathrm{C}(30 \mathrm{~s})$ and $54{ }^{\circ} \mathrm{C}(30 \mathrm{~s}) / 72{ }^{\circ} \mathrm{C}(1 \mathrm{~min})$ were applied.

The final melting analysis was achieved by slow heating from $65^{\circ} \mathrm{C}$ to $95^{\circ} \mathrm{C}$ in order to assess the specificity of the prime sets (Applied Biosystems, Foster City, CA, USA). The change in the quantity of target species in a tested sample (SARA or SCFP sample) relative to the same target species in a calibrator sample (Normal sample or No-SCFP sample) was calculated after all data were normalized for Eubacteria using the bacterial $16 \mathrm{~S}$ RNA gene primer sets, which detect all bacterial strains. The efficiency of the amplification of each primer set was calculated from the slope of the standard curve generated with pool DNA samples and listed in Supplementary Table S2.

\section{Other statistical analyses}

The effects of the SARA challenge and SCFP supplementation on all microbial variables, relative abundance of microbial populations, diversity indices, and metabolic functions of microbiome were analyzed in SAS (Ver. 9.3, SAS Inst., Inc., Cary, NC). The experimental unit was individual cow. Data were analyzed using a crossover and repeated measures design with the PROC MIXED procedure of SAS. The model included period, diet (Control or SARA), treatment (NoSCFP or SCFP) and all two and three-way (when appropriate) interactions as fixed factors. If the interaction term was not statistically significant $(P>0.05)$, it was excluded from the final model. The effects of cow and cow $\times$ diet $\times$ treatment were considered random. The PDIFF option was applied to evaluate pairwise comparisons between weeks, treatments, and diet $\times$ treatment interaction. Measurements collected at different sampling times on the same cow were considered repeated measures and the AR1 covariance structure was followed as this resulted in the smallest setting Bayesian information criterion. The normality of distributions of error terms were tested using the Shapiro-Wilks statistics using Proc UNIVARIATE. If the error terms were not normally distributed, then the data were transformed by raising it to the power of lambda. The required lambda value was the value calculated by 
Box-Cox transformation analysis using the TRANSREG procedure of SAS.

Data of the in vitro study were expressed as fold changes over the control treatment, and the effects of the SCFP treatment (XPC or NutriTek) on these changes were tested using the MIXED procedure of SAS. These analyses were conducted for each of the bacterial species and by incubation $\mathrm{pH}$ (High or Depressed $\mathrm{pH})$. The effects of treatment were considered fixed, whereas the effects of duplicate run in the model of the Low $\mathrm{pH}$ were considered random. For all statistical analyses, effects were declared significant at $P<0.05$, and tendencies at $P<0.10$ were discussed.

\section{Supplementary information}

Supplementary information accompanies this paper at https://doi.org/10. 1186/s12917-020-02437-w.

Additional file 1: Table S1. The primer sets used for quantitative PCR ( $\mathrm{PPCR}$ ) in the in-vitro study. Table S2. The primer sets used for quantitative PCR ( $(\mathrm{PCR})$ in the in-vivo study. TableS3. Relative abundances of bacterial phyla of microbial communities in the rumen affected by Saccharomyces cerevisiae fermentation products (SCFP) and subacute ruminal acidosis (SARA) challenge.

\section{Abbreviations}

BW: Body weight; CCAC: Canadian Council on Animal Care; DNA : Deoxyribonucleic acid; FDH: Formate dehydrogenase; HSD: Honest significance test; LDA: Linear discriminant analysis; LEfSe: Linear Discriminant Analysis with Effect Size; LPS: Lipopolysaccharide; MCM: Methylmalonyl-CoA mutase; nMDS: Nonmetric multidimensional scaling plots; OTU: Operational taxonomic unit; PCoA: Principal coordinates analysis; PERMANOVA: Permutational multivariate analyses of variance; qPCR: quantitative polymerase chain reaction; SARA: Subacute ruminal acidosis; SCFP: Saccharomyces cerevisiae fermentation products; VFA: Volatile fatty acids

\section{Acknowledgements}

We would like to thank Terri Garner, Deane Fulawka, and the staff of the Glenlea Dairy Barn for their technical assistance.

\section{Authors' contributions}

JCP, IY and EK conceived and designed the experiment. SL and HMT performed lab analyses. EK, HMT, PA and SL developed the bioinformatics and statistical models. HMT and SL analyzed the data. SM, HMT, SL, PA, EK and JCP wrote the manuscript. HMT and SL contributed equally to the research. All authors have read and approved the manuscript.

\section{Funding}

This study was supported by grant ARDI10-1053 from the Agri-Food Research Development Initiative, Discovery Grant 238454 of the Natural Sciences and Engineering Research Council of Canada, and a grant from Diamond V, Cedar Rapids, IA. Diamond V had a role in the design of the study, in editing and approving the submission of the final manuscript, but not in the implementation of the experiment, or the collection and analysis of the data. The other funding agencies did not have a role in the design, implementation, collection and interpretation of data, and manuscript preparation related to the study.

\section{Availability of data and materials}

All sequencing data are deposited into the European Nucleotide Archive (ENA) (http://www.ebi.ac.uk/ena) of European Molecular Biology LaboratoryEuropean Bioinformatic Institute (EMBL-EBI) and can be accessed via accession number ERP117106.

\section{Ethics approval and consent to participate}

The study was approved by the University of Manitoba Animal Care Committee and.

followed the guidelines of the Canadian Council for Animal Care (CCAC, Ottawa, ON, Canada).

\section{Consent for publication}

Not applicable.

\section{Competing interests}

Dr. Yoon is the Director of Ruminant Research at Diamond V. Dr. Khafipour was an Associate Professor at the University of Manitoba when the study was conducted. He is currently the Director of Microbiome Research at Diamond V.

\section{Author details}

'Department of Animal Science, University of Manitoba, Winnipeg, MB, Canada. ${ }^{2}$ Present address: HKU-Pasteur Research Pole, School of Public Health, Li Ka Shing Faculty of Medicine, The University of Hong Kong, Hong Kong, Hong Kong SAR. ${ }^{3}$ Diamond V, Cedar Rapids, IA, USA. ${ }^{4}$ School of Agriculture and Food Science, University of Queensland Gatton campus, Gatton, Australia. ${ }^{5}$ Present Address: Diamond V, Cedar Rapids, IA, USA.

Received: 29 March 2019 Accepted: 18 June 2020

Published online: 11 July 2020

\section{References}

1. Plaizier JC, Khafipour E, Li S, Gozho GN, Krause DO. Subacute ruminal acidosis (SARA), endotoxins and health consequences. Anim Feed Sci Technol. 2012;172:9-21.

2. Russell JB, Rychlik JL. Factors that alter rumen microbial ecology. Science. 2001:292:1119-22.

3. Mao SY, Zhang RY, Wang DS, Zhu WY. Impact of subacute ruminal acidosis (SARA) adaptation on rumen microbiota in dairy cattle using pyrosequencing. Anaerobe. 2013;24:12-9.

4. Plaizier JC, Krause DO, Gozho GN, McBride BW. Subacute ruminal acidosis in dairy cows: the physiological causes, incidence and consequences. Vet J. 2008;176:21-31.

5. Hook SE, Steele MA, Northwood KS, Dijkstra J, France J, Wright AD, McBride BW. Impact of subacute ruminal acidosis (SARA) adaptation and recovery on the density and diversity of bacteria in the rumen of dairy cows. FEMS Micro Ecol. 2011;78:275-84

6. Callaway ES, Martin SA. Effects of a Saccharomyces cerevisiae culture on ruminal bacteria that utilize lactate and digest cellulose. J Dairy Sci. 1997;80: 2035-44.

7. Arakaki L, Stahringer R, Garrett J, Dehority B. The effects of feeding monensin and yeast culture, alone or in combination, on the concentration and generic composition of rumen protozoa in steers fed on low-quality pasture supplemented with increasing levels of concentrate. Anim Feed Sci Technol. 2000;84:121-7.

8. Wiedmeier RD, Arambel MJ, Walters JL. Effect of yeast culture and Aspergillus oryzae fermentation extract on ruminal characteristics and nutrient digestibility. J Dairy Sci. 1987;70:2063-8.

9. Li S, Yoon I, Scott M, Khafipour E, Plaizier JC. Impact of Saccharomyces cerevisiae fermentation product and subacute ruminal acidosis production, inflammation, and fermentation in the rumen and hindgut of dairy cows. Anim Feed Sci Technol. 2016;211:50-60.

10. Plaizier JC, Li S, Tun HM, Khafipour E. Nutritional models of experimentallyinduced subacute ruminal acidosis (SARA) differ in their impact on rumen and hindgut bacterial communities in dairy cows. Front Microbiol. 2016;7: 2128.

11. Plaizier JC, Li S, Danscher AM, Derakshani H, Andersen PH, Khafipour E. Changes in microbiota in rumen digesta and feces due to a grain-based subacute ruminal acidosis (SARA) challenge. Microb Ecol. 2017;74(2):485-95.

12. El Kaoutari A, Armougom F, Leroy Q, Vialettes B, Million M, Raoult D, Henrissat B. Development and validation of a microarray for the investigation of the CAZymes encoded by the human gut microbiome. PLoS One. 2013;8:e84033.

13. Petri RM, Schwaiger T, Penner GB, Beauchemin KA, Forster RJ, MCKinnon JJ, McAllister TA. Characterization of the core rumen microbiome in cattle 
during transition from forage to concentrate as well as during and after an acidotic challenge. PLoS One. 2013;8:e83424.

14. Fernando SC, Purvis HT, Najar FZ, Sukharnikov LO, Krehbiel CR, Nagaraja TG, Roe BA, DeSilva U. Rumen microbial population dynamics during adaptation to a high-grain diet. Appl Environ Microbiol. 2010;76:7482-90.

15. Khafipour E, Li S, Plaizier JC, Krause DO. Rumen microbiome composition determined using two nutritional models of subacute ruminal acidosis. Appl Environ Microbiol. 2009;75:7115-24.

16. Shah N, Tang H, Doak TG, Ye Y. Comparing bacterial communities inferred from 165 rRNA gene sequencing and shotgun metagenomics. Pac Symp Biocomput. 2011;1:165-76

17. Highlander SK. High throughput sequencing methods for microbiome profiling: application to food animal systems. Anim Health Res Rev. 2012;13: 40-53.

18. Mullins CR, Mamedova LK, Carpenter AJ, Ying Y, Allen MS, Yoon I, Bradford BJ. Analysis of rumen microbial populations in lactating dairy cattle fed diets varying in carbohydrate profiles and Saccharomyces cerevisiae fermentation product. J Dairy Sci. 2013;96:5872-81.

19. Weimer PJ. Redundancy, resilience, and host specificity of the ruminal microbiota: implications for engineering improved ruminal fermentations. Front Microbiol. 2015;6:296

20. Prins RA, van Rheenen DL, van't Klooster AT. Characterization of microbial proteolytic enzymes in the rumen. Antonie Van Leeuwenhoek. 1983:49:585-95.

21. Huntington GB, Archibeque SL. Practical aspects of urea and ammonia metabolism in ruminants. J Anim Sci. 2000;77:1-11.

22. Karami A, Sarshar M, Ranjbar R, Zanjani RS. In: Rosenberg E, editor. The prokaryotes: other major lineages of bacteria and the archaea. Germany: Springer Berlin Heidelberg; 2014. p. 915-29.

23. De Vos PA, Ludwig WO, Schleifer KH, Whitman WB IV. Family IV. Paenibacillaceae fam nov. Bergey's Manual Syst Bacteriol. 2011;3:269.

24. Wood GE, Haydock AK. Leigh. A function and regulation of the formate dehydrogenase genes of the methanogenic archaeon Methanococcus maripaludis. J Bacteriol. 2003;185:2548-54.

25. Degnan PH, Taga ME, Goodman AL. Vitamin B12 as a modulator of gut microbial ecology. Cell Metab. 2014;20:769-78

26. Takahashi-Iniguez T, Garcia-Hernandez E, Arreguin-Espinosa R, Flores ME. Role of vitamin B12 on methylmalonyl-CoA mutase activity. J Zhejiang Univ (Sci). 2013;13:423-37.

27. Ghouri YA, Richards DM, Rahimi EF, Krill JT, Jelinek KA, DuPont AW. Systematic review of randomized controlled trials of probiotics, prebiotics, and synbiotics in inflammatory bowel disease. Clin Exp Gastroenterol. 2014; 7:473-87.

28. Dehority BA. Rumen microbiology. Nottingham: Nottingham University Press; 2003.

29. Henderson G, Cox F, Ganesh S, Jonker A, Young W, Abecia L, Angarita E, Aravena P, Arenas GN, Ariza C, Attwood GT. Rumen microbial community composition varies with diet and host, but a core microbiome is found across a wide geographical range. Sci Rep. 2015;5:14567.

30. Xiao JX, Alugongo GM, Chung R, Dong SZ, Li SL, Yoon I, Wu ZH, Cao ZJ. Effects of Saccharomyces cerevisiae fermentation products on dairy calves: Ruminal fermentation, gastrointestinal morphology, and microbial community. J Dairy Sci. 2016;99:5401-12.

31. Sullivan HM, Martin SA. Effects of a Saccharomyces cerevisiae culture on in vitro mixed ruminal microorganism fermentation. J Dairy Sci. 1999;82:2011-6.

32. CCAC. Guide to the Care and Use of Experimental Animals, vol. 1. 2nd ed. Ottawa: Canadian Council on Animal Care; 1993.

33. Pu S, Jones PJ, Khazanehei HR, Khafipour E. Dietary monounsaturated and polyunsaturated oils on human gut microbiome profiles in the canola oil multicenter intervention trial (COMIT). Front Microbiol. 2016;7:1612.

34. Caporaso JG, Kuczynski J, Stombaugh J, Bittinger K, Bushman FD, Costello EK, Fierer N, Pena AG, Goodrich JK, Gordon JI, Huttley GA. QIIME allows analysis of high-throughput community sequencing data. Nature Meth. 2010;7:335-6.

35. Edgar RC, Haas BJ, Clemente JC, Quince C, Knight R. UCHIME improves sensitivity and speed of chimera detection. Bioinformatics. 2011;27: 2194-200.

36. McDonald D, Price MN, Goodrich J, Nawrocki EP, DeSantis TZ, Probst A, Andersen GL, Knight R, Hugenholtz P. An improved Greengenes taxonomy with explicit ranks for ecological and evolutionary analyses of bacteria and archaea. ISME J. 2012;6:610-8.
37. Caporaso JG, Bittinger K, Bushman FD, DeSantis TZ, Andersen GL, Knight R. PyNAST: a flexible tool for aligning sequences to a template alignment. Bioinformatics. 2010;26:266-7.

38. Price MN, Dehal PS, Arkin AP. FastTree: computing large minimum evolution trees with profiles instead of a distance matrix. Molec Bio Evol. 2009;26: $1641-50$.

39. Lozupone C, Lladser ME, Knights D, Stombaugh J, Knight R. UniFrac: an effective distance metric for microbial community comparison. ISME J. 2011; 5:169-72.

40. Wang Q, Garrity GM, Tiedje JM, Cole JR. Naive Bayesian classifier for rapid assignment of rRNA sequences into the new bacterial taxonomy. Appl Environ Microbiol. 2007;73:5261-7.

41. McMurdie PJ, Holmes S. Phyloseq: an R package for reproducible interactive analysis and graphics of microbiome census data. PLoS One. 2013;8:e61217.

42. Carcer DA, Denman SE, McSweeney C, Morrison M. Evaluation of subsampling-based normalization strategies for tagged high-throughput sequencing data sets from gut microbiomes. Appl Environ Microbiol. 2011; 77:8795-8.

43. Tun HM, Brar MS, Khin N, Jun L, Hui RK, Dowd SE, Leung FC. Gene-centric metagenomics analysis of feline intestinal microbiome using 454 junior pyrosequencing. J Microbiol Methods. 2012;88:369-76.

44. Elsik CG, Tayal A, Diesh CM, Unni DR, Emery ML, Nguyen HN, Hagen DE. Hymenoptera genome database: integrating genome annotations in HymenopteraMine. Nucleic Acids Res. 2016;44:D793-800.

45. Wilke A, Bischof J, Gerlach W, Glass E, Harrison T, Keegan KP, Paczian T, Trimble WL, Bagchi S, Grama A, Chaterii S. The MG-RAST metagenomics database and portal in 2015. Nucleic Acids Res. 2016;44(D1):D590-4.

46. Segata N, Izard J, Waldron L, Gevers D, Miropolsky L, Garrett WS, Huttenhower C. Metagenomic biomarker discovery and explanation. Genome Biol. 2011;12:R60.

\section{Publisher's Note}

Springer Nature remains neutral with regard to jurisdictional claims in published maps and institutional affiliations.

\section{Ready to submit your research? Choose BMC and benefit from:}

- fast, convenient online submission

- thorough peer review by experienced researchers in your field

- rapid publication on acceptance

- support for research data, including large and complex data types

- gold Open Access which fosters wider collaboration and increased citations

- maximum visibility for your research: over $100 \mathrm{M}$ website views per year

At $\mathrm{BMC}$, research is always in progress.

Learn more biomedcentral.com/submissions 